\title{
CRITICALITY CHARACTERISTICS OF MIXTURES OF PLUTONIUM, SILICON DIOXIDE, NEVADA TUFF, AND WATER
}

\author{
R. Sanchez, W. Myers, D. Hayes, R. Kimpland, P. Jaegers, \\ R. Paternoster, S. Rojas, R. Anderson, and W. Stratton \\ Los Alamos National Laboratory
}

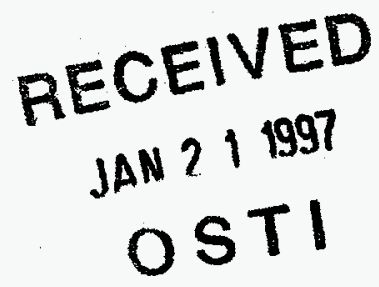

DISCLAIMER

\begin{abstract}
This report was prepared as an account of work sponsored by an agency of the United States Government. Neither the United States Government nor any agency thereof, nor any of their employees, makes any warranty, express or implied, or assumes any legal liability or responsibility for the accuracy, completeness, or usefulness of any information, apparatus, product, or process disclosed, or represents that its use would not infringe privately owned rights. Reference herein to any specific commercial product, process, or service by trade name, trademark, manufacturer, or otherwise does not necessarily constitute or imply its endorsement, recommendation, or favoring by the United States Government or any agency thereof. The views and opinions of authors expressed herein do not necessarily state or reflect those of the United States Government or any agency thereof.
\end{abstract}




\section{DISCLAIMER}

Portions of this document may be illegible in electronic image products. Images are produced from the best available original document. 


\section{Table of Contents}

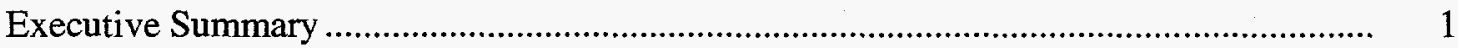

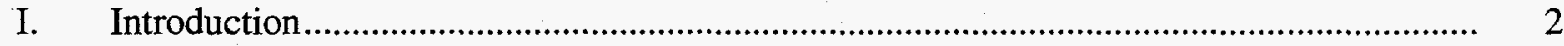

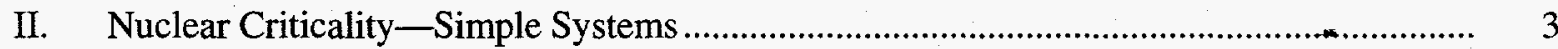

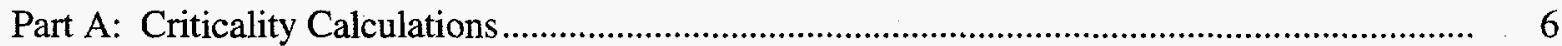

III. Nuclear Criticality — Other Materials .............................................................................. 6

IV. Criticality Calculations for Plutonium- $\mathrm{SiO}_{2}-\mathrm{H}_{2} \mathrm{O},-\mathrm{a}$ Three-Component System …........ $\quad 8$

V. Constraints on the Possible Critical Configurations ..............................................................

VI. Reactivity $\left(k_{\text {eff }}\right)$ Calculations .................................................................................. 18

Part B: Criticality Calculations for Plutonium, Tuff, and Water .............................................. 21

VII. Nuclear Criticality, Plutonium-Tuff ....................................................................... 21

VIII. Criticality Calculations for Pu-Tuff- $\mathrm{H}_{2} \mathrm{O}$, a Three Component System ............................ 24

IX. Discussion of Postulates ................................................................................................ 28

X. Reactivity $\left(k_{\text {eff }}\right)$ Calculations for Pu-Tuff- $\mathrm{H}_{2} \mathrm{O}$ Mixtures................................................ 29

XI. Summary and Conclusions .......................................................................................... 32

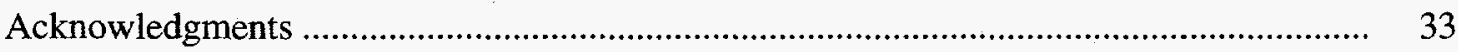

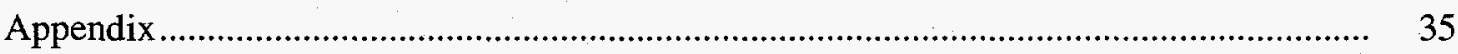

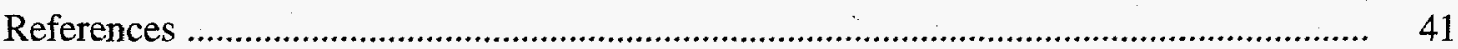




\title{
CRITICALITY CHARACTERISTICS OF MIXTURES OF PLUTONIUM, SILICON DIOXIDE, NEVADA TUFF, AND WATER
}

\author{
R. Sanchez, W. Myers, D. Hayes, R. Kimpland, P. Jaegers, \\ R. Paternoster, S. Rojas, R. Anderson, and W. Stratton \\ Los Alamos National Laboratory
}

\section{EXECUTIVE SUMMARY}

The major objective of this study has been to examine the possibility of a nuclear explosion (and evaluate this event if it is possible) should 50 to $100 \mathrm{~kg}$ of plutonium be mixed with $\mathrm{SiO}_{2}$, vitrified, placed within a heavy steel container, and buried in the material known as Nevada tuff. To accomplish this objective we have created a survey of the critical states or configurations of mixtures of plutonium, $\mathrm{SiO}_{2}$, tuff, and water and examined these data to isolate those configurations that might be unstable or autocatalytic. The survey of critical data now exists and is published herein. We identify regions of criticality instability with the possibility of autocatalytic power behavior (the existence of such autocatalytic phenomena is not new). Autocatalytic power behavior is possible for a very limited range of wet systems, but this behavior is improbable. A quantitative and conservative evaluation of the fission power behavior of these autocatalytic mixtures shows that no explosion should be expected.

Three basic modes of mixing plutonium, tuff, $\mathrm{SiO}_{2}$, and water were postulated in Refs. 1, 2, and 3 . These are as follows:

1. expansion of the plutonium into a larger mass of Nevada tuff (or $\mathrm{SiO}_{2}$ ) under dry conditions,

2. movement of water into a volume of plutonium/tuff (or $\mathrm{SiO}_{2}$ ) mixture of nearly any atom ratio of silicon to plutonium, and

3. movement of plutonium moving into a stratum of tuff (or $\mathrm{SiO}_{2}$ ) that contains an appropriate amount of water.

Each of these scenarios requires a breach of the original container, disintegration of the vitreous log, and for cases 1 and 3, further movement and mixing of the plutonium into tuff $\left(\mathrm{SiO}_{2}\right)$.

Case 1 requires more plutonium to be stored than has been suggested; if sufficient plutonium should be available, an extraordinary or impossibly rapid expansion of $\mathrm{PuO}_{2}$ molecules at high velocity through large, solid masses of tuff or $\mathrm{SiO}_{2}$ is also required. Criticality is possible but highly improbable, given realistic assumptions for masses and compositions; autocatalysis requires additional unphysical assumptions. No explosion should be expected. It is specifically shown in a companion paper that no explosion results even with these assumptions for the only detailed scenario described in Refs. 1, 2, and 3.

Case 2 requires that the vitreous log disintegrates and that water enters the system. Mixing with more tuff $\left(\mathrm{SiO}_{2}\right)$ may or may not have occurred. This case would be the plutonium equivalent of the Oklo phenomenon of two or more billion years ago (Ref. 4). A critical system is possible, but autocatalysis is not possible, and an explosion is not possible.

Case 3 requires breach of the container, disintegration of the vitreous $\log$, and movement of $\mathrm{PuO}_{2}$ with or without $\mathrm{SiO}_{2}$ into a stratum of tuff $\left(\mathrm{SiO}_{2}\right)$ that contains an appropriate amount of water. This process could lead to critical configurations that could be unstable with the possibility of an autocatalytic power response. Criticality constraints and constraints based on the amount of fissile mater-ial and water 
content of the tuff $\left(\mathrm{SiO}_{2}\right)$ severely limit the possibilities. Those remaining configurations have been examined for a worst case. A critical system is possible, and autocatalysis is possible, but no explosion should be expected.

This study has adopted highly conservative positions with respect to both nuclear and geologic assumptions. A more realistic treatment of nuclear assumptions is expected to severely constrain the possibilities for criticality and autocatalytic behavior. The probabilities and even the possibilities of the several geologic and chemical phenomena and actions that must occur before a criticality study is even appropriate are not evaluated in this paper. These chemical and geologic considerations_studies underway, see Ref. 5) may eliminate the problem and the need for a criticality and dynamic study completely.

\section{INTRODUCTION}

The nuclear criticality characteristics of mixtures of plutonium, silicon dioxide, and water (Part A) or plutonium, silicon dioxide, Nevada Yucca Mountain tuff, and water (Part B) have become of interest because of the appearance of recent papers on the subject (Refs. 1,2, and 3). These papers postulate that if excess weapons plutonium is vitrified into a silicate log and buried underground, a self-sustaining neutron chain reaction may develop given sufficient time and interaction with the burial medium. Moreover, given specific geologic actions resulting in postulated configurations, the referenced papers state that nuclear explosions could occur with multi-kiloton yields (Ref. 1) or yields equivalent to hundreds of tons of TNT (Ref. 3). (References 1 and 2 are draft documents that were distributed widely; Ref. 3 has been submitted to a professional journal for publication.)

The objectives of this paper (and the companion papers on dynamics) are as follows:

1. to examine the possibility of a nuclear explosion (and evaluate this event if it is possible) should several kilograms of plutonium be mixed with $\mathrm{SiO}_{2}$, vitrified, placed within a heavy steel container, and buried in the material known as Nevada tuff;

2. to establish the parameters (density, moderation, reflection, poisons, and dilution with nonfissile material) that determine when mixtures of ${ }^{239} \mathrm{Pu}, \mathrm{SiO}_{2}$, and water (Part A) and mixtures of ${ }^{239} \mathrm{Pu}$, Nevada tuff, and water (Part B) are critical, i.e., are capable of sustaining a continuing neutron chain reaction without change of fission power;

3. to examine these results to find those configurations that may be unstable or "autocatalytic" (the critical state in which an increase in fission power leads automatically to a further increase of reactivity and, hence, greater fission power); and

4. to establish the restrictions or constraints on these parameters that are required by criticality physics, the amount of plutonium postulated to be stored, and possible water content in the Nevada tuff.

Given these conditions, the companion paper on dynamics will examine possibilities for and possible consequences of an uncontrolled fission power transient, using calculational methods that have been developed to study power transient dynamics of pulsed assemblies or reactors and criticality accidents.

Part $\mathrm{A}$ of this paper will concentrate on the pure $\mathrm{SiO}_{2}$ diluent, while in Part $\mathrm{B}$, criticality computations have been completed using the actual elemental composition of Nevada Yucca Mountain tuff (see Ref. 6). Tuff contains many elements, including neutron poisons, which place additional constraints on the postulated situations in Refs. 1, 2, and 3. 
The calculations presented in this paper assume homogeneous spherical distributions with pure $\mathrm{Pu}-239$ as the fissile material. This is a conservative assumption when dealing with static or near-static criticality phenomena because the critical masses for pure $\mathrm{Pu}-239$ are substantially lower than those for U-235 and also lower than for weapons-grade plutonium. In addition, any significant heterogeneity of the plutonium is expected to reduce the reactivity of the system significantly (even enough to preclude criticality in some cases).

By critical, or the critical state, we mean that the system can just maintain an existing fission rate or power without change; by supercritical, we mean that the fission rate would be increasing; and by subcritical, we mean that the fission rate, if it exists, would be decreasing to zero power or to a near-zero power if an intrinsic source were present in the material.

Additional calculated critical mass data have been included for clarity and understanding.

Most of the computations in this paper have been completed by use of the ONEDANT neutron transport computer program (Ref. 7), a modern version of the classic system created by Bengt Carlson (Ref. 8). More details of models and computational methods are given in the Appendix.

\section{NUCLEAR CRITICALITY -SIMPLE SYSTEMS}

To introduce the discussion of nuclear criticality parameters for a three-component system, it is useful to begin with illustrations of the criticality properties of a simple two-component system that is more familiar than mixtures of plutonium, $\mathrm{SiO}_{2}$ or tuff, and water. Thus, in Fig. 1, the critical mass of plutonium metal mixed with water is illustrated as a function of the density of plutonium in the water (Ref. 13). The mixture is idealized to be only metal and water at room temperature; actual solutions of plutonium compounds would differ but little. Both water-reflected (20-cm thickness) and unreflected (bare) systems are shown. The general characteristics illustrated are similar for nearly all diluents of fissile material: ${ }^{235} \mathrm{U},{ }^{233} \mathrm{U}$, or ${ }^{239} \mathrm{Pu}$. The initial effect of the diluent (water in this case) is to reduce the density of the plutonium, thus allowing greater neutron leakage and requiring a larger mass of fissile material to achieve the critical state. A maximum critical mass (about $9 \mathrm{~kg}$ for the reflected case) can be seen at a plutonium density of $\sim 6 \mathrm{~g} / \mathrm{cm}^{3}(\mathrm{~kg} / \mathrm{l})$ where the moderating property of the hydrogen dominates the loss of neutrons due to leakage or absorption. As still more diluent is added, the moderating power of hydrogen causes the critical mass to decrease to a minimum value (about $500 \mathrm{~g}$ at a plutonium density of $0.03 \mathrm{~kg} / \mathrm{l}$ for the reflected case) at which point the moderating and absorptive properties of the diluent balance. With more dilution, the absorption cross-section of hydrogen dominates, and the mass required for criticality increases until finally an asymptote is reached, which establishes the limiting density for dilution; both the mass and volume are unbounded. The limiting value of the density is an important property that will be useful in later discussions. For plutonium-water mixtures, the asymptote is at about $0.007 \mathrm{~kg} / \mathrm{l}$ and, obviously, both the bare and reflected cases converge to this same value. These data are very well established by experiment (Ref. 13) and the computational scheme is well established by comparing calculational results with experimental results (Ref. 12). However, there is less critical data near the asymptote because of the progressively larger size of the experimental vessel required. 


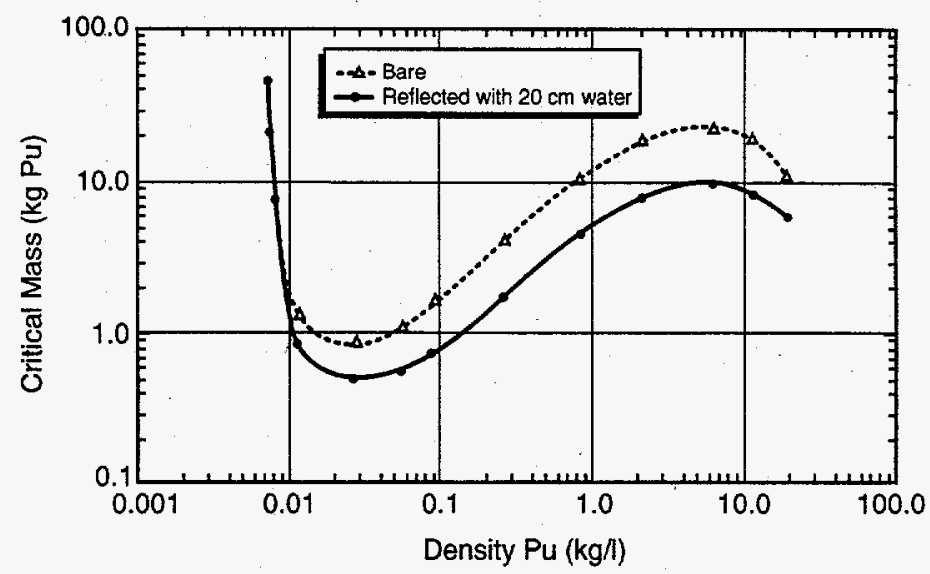

Figure 1. Critical mass of plutonium metal as a function of plutonium density when mixed with water. (room temperature) The plutonium is idealized to be a sphere with a finegrain powder and mixed uniformly with the water. The data defining the low-density asymptote are new for this study. The major body of data was taken from Ref. 12 and is reproduced in Table I. An important characteristic to note is the minimum critical mass at a plutonium density of about $0.03 \mathrm{~kg} / \mathrm{l}$.

Table I. ${ }^{239}$ Pu Metal-Water Mixtures: Critical Parameters for Bare and Water-Reflected Spheres at Room Temperature

\begin{tabular}{|c|c|c|c|c|c|c|c|}
\cline { 2 - 8 } \multicolumn{1}{c|}{} & \multicolumn{4}{c|}{ Unreflected } & \multicolumn{3}{c|}{ Water Reflected } \\
\hline $\begin{array}{c}\mathbf{H} /^{\mathbf{2 3 9}} \mathbf{P u} \\
\text { Atom ratio) }\end{array}$ & $\begin{array}{c}\text { Pu Density } \\
(\mathbf{k g} / \mathbf{)}\end{array}$ & $\begin{array}{c}\text { Radius } \\
(\mathbf{c m})\end{array}$ & $\begin{array}{c}\text { Volume } \\
(\text { liter })\end{array}$ & $\begin{array}{c}\text { Mass } \\
(\mathbf{k g})\end{array}$ & $\begin{array}{c}\text { Radius } \\
(\mathbf{c m})\end{array}$ & $\begin{array}{c}\text { Volume } \\
(\text { liter) }\end{array}$ & $\begin{array}{c}\text { Mass } \\
(\mathbf{k g} \text { Pu) }\end{array}$ \\
\hline 0.0 & $1.97 \times 10^{1}$ & 4.90 & 0.49 & 9.71 & 3.98 & $2.64 \times 10^{-1}$ & 5.20 \\
\hline $1.00 \times 10^{0}$ & $1.13 \times 10^{1}$ & 7.15 & 1.53 & 17.3 & 5.48 & $6.89 \times 10^{-1}$ & 7.79 \\
\hline $3.00 \times 10^{0}$ & $6.11 \times 10^{0}$ & 9.38 & 3.46 & 21.1 & 7.04 & $1.46 \times 10^{0}$ & 8.93 \\
\hline $1.00 \times 10^{1}$ & $2.34 \times 10^{0}$ & 12.2 & 7.61 & 17.8 & 9.06 & $3.12 \times 10^{0}$ & 7.29 \\
\hline $3.00 \times 10^{1}$ & $8.46 \times 10^{-1}$ & 14.1 & 11.7 & 9.93 & 10.5 & $4.85 \times 10^{0}$ & 4.10 \\
\hline $1.00 \times 10^{2}$ & $2.62 \times 10^{-1}$ & 15.1 & 14.4 & 3.78 & 11.4 & $6.21 \times 10^{0}$ & 1.63 \\
\hline $3.00 \times 10^{2}$ & $8.81 \times 10^{-2}$ & 16.1 & 17.5 & 1.54 & 12.5 & $8.18 \times 10^{0}$ & 0.72 \\
\hline $5.00 \times 10^{2}$ & $5.29 \times 10^{-2}$ & 17.0 & 20.6 & 1.09 & 13.5 & $1.03 \times 10^{1}$ & 0.55 \\
\hline $1.00 \times 10^{3}$ & $2.65 \times 10^{-2}$ & 19.8 & 32.5 & 0.86 & 16.4 & $1.85 \times 10^{1}$ & 0.49 \\
\hline $2.00 \times 10^{3}$ & $1.33 \times 10^{-2}$ & 28.1 & 92.9 & 1.23 & 24.7 & $6.31 \times 10^{1}$ & 0.84 \\
\hline $3.32 \times 10^{3}$ & $8.00 \times 10^{-3}$ & & & & 61.05 & $9.53 \times 10^{2}$ & 7.62 \\
\hline $3.54 \times 10^{3}$ & $7.50 \times 10^{-3}$ & & & & 87.2 & $2.78 \times 10^{3}$ & 20.8 \\
\hline $3.64 \times 10^{3}$ & $7.30 \times 10^{-3}$ & & & & 113.47 & $6.12 \times 10^{3}$ & 44.7 \\
\hline $3.74 \times 10^{3}$ & $7.10 \times 10^{-3}$ & & & & 198.3 & $3.27 \times 10^{4}$ & 232.0 \\
\hline
\end{tabular}


- The presence of water has a significant effect on the critical mass. It is this sharp dependence of the ${ }^{239} \mathrm{Pu}$ critical mass on the moderator content (in this instance, the hydrogen content) of the system that makes the analyses of criticality phenomena so complex. A wide variety of results are possible. For example, the critical mass of a plutonium metal ball with a water reflector is given in Table I as about $5.2 \mathrm{~kg}$, while the critical mass of a plutonium solution with the same water reflector is about $0.5 \mathrm{~kg}$. Under more unusual and extraordinary circumstances, (non-absorbing diluents and cryogenic temperatures) the critical mass might be significantly lower.

Illustrating the critical masses of fissile metals mixed in water in this manner is well established; to our knowledge, data similar to these were first calculated in late 1942 by J. Robert Oppenheimer (Ref. 14). In the 1950s nuclear criticality data were summarized and published by H. Paxton of Los Alamos and D. Callihan of Oak Ridge (the two architects of the science of criticality physics and safety, see Ref. 13), and this manner of presentation became common usage. These same data, however, can be presented in different formats to illustrate different criticality properties. In Fig. 2, the critical volume of ${ }^{239} \mathrm{Pu}$ in water is illustrated as a function of the plutonium density (the critical volume increases monotonically with decreasing plutonium density) and in Fig. 3, the critical mass is shown as a function of the critical volume. The data for Figs. 1, 2, and 3 are given in Table I.

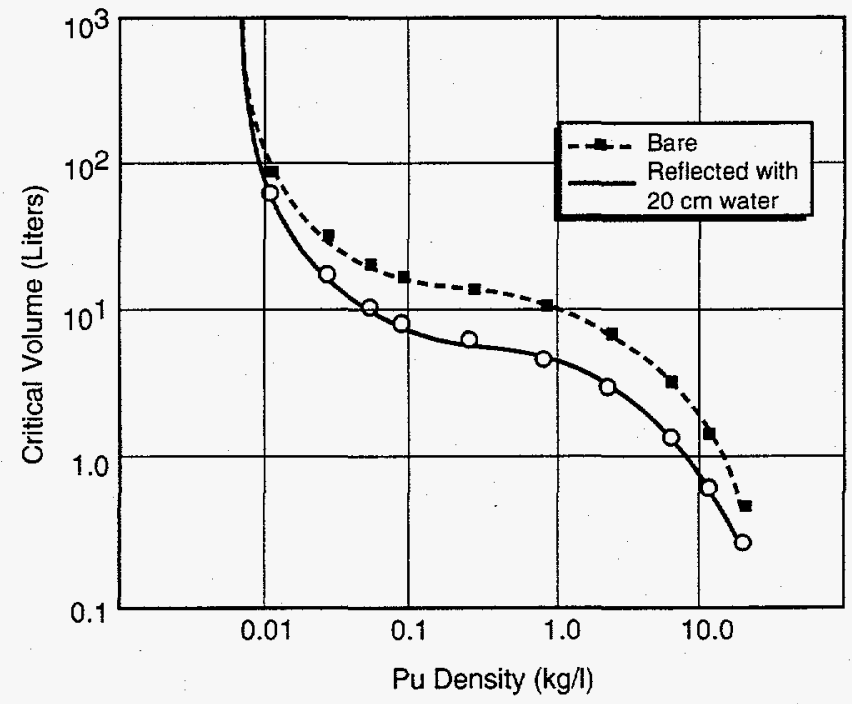

Figure 2. Critical volume of plutonium-water mixtures as a function of the plutonium density. (room temperature).

Figure 3. Critical mass of $\mathrm{Pu}-\mathrm{H}_{2} \mathrm{O}$ mixtures as a function of the critical volume of the mixture (room temperature).

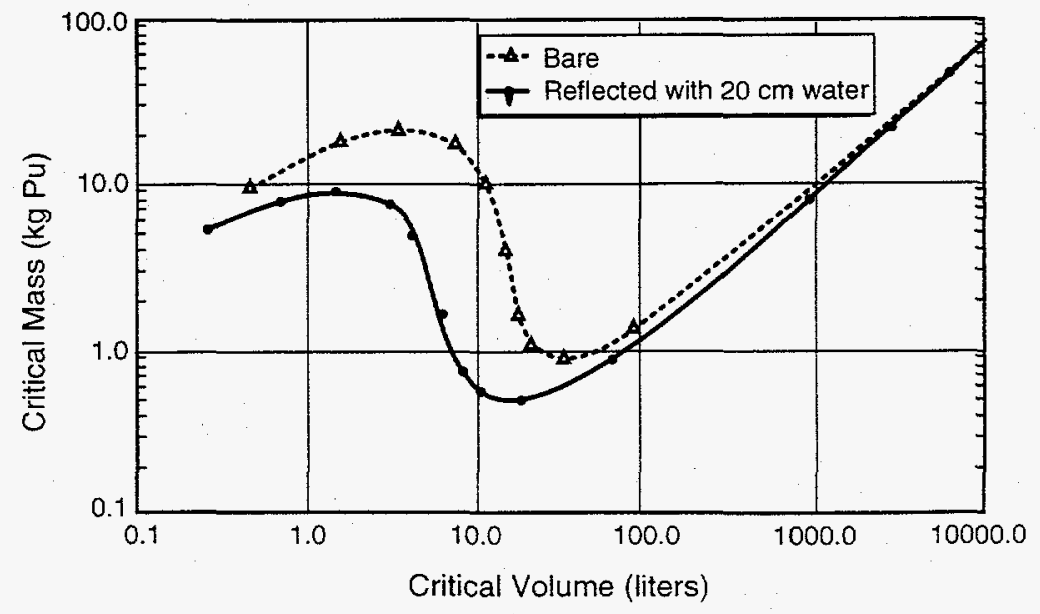


Each representation is useful in understanding the influence of various parameters and in establishing. conditions of nuclear criticality stability or possible instability. For example, if a slightly supercritical plutonium- $\mathrm{H}_{2} \mathrm{O}$ mixture should be created at a density just greater than the low-density asymptote (choose about $10 \mathrm{~kg}$ and a density of about $0.008 \mathrm{~kg} / \mathrm{l}$ ) the solution would heat and lose water, thus decreasing the volume and increasing the plutonium density. Given only these two effects, the system would now be at a very high reactivity and power would increase. However, any decrease of volume caused by water loss would be balanced by boiling and expansion, thus reducing reactivity. The net result is boiling, just maintaining criticality. This would continue until the system is dry enough to be subcritical. More complex dynamic behavior is possible depending on such factors as fission product producing currents caused by convection or bubbling, plutonium depletion, etc.,An example is given in the Appendix of the companion paper on dynamics. This condition is often referred to as "unstable" or "autocatalytic." Another example of an interesting, although not unstable condition, is the region in Fig. 1 between densities of about 1.0 and $0.08 \mathrm{~kg} / \mathrm{l}$. If water, which is a diluent, moderator, and absorber, is added, a supercritical state is created. This same situation can be seen in Fig. 3 between volumes of about 3 and 81 where, if the volume should be increased by the addition of water, a supercritical state is created. However, this is not autocatalytic like the first example; thermal expansion, possibly with boiling, would reduce reactivity to return the system to subcriticality; little change of composition would occur.

\section{PART A: CRITICALITY CALCULATIONS PLUTONIUM, SILICON DIOXIDE, AND WATER}

\section{NUCLEAR CRITICALITY — OTHER MATERIALS}

As mentioned above, the general characteristics of Figs. 1,2, and 3 can be seen when other materials (some good moderators and some indifferent moderators) are used as a diluent. Examples are illustrated in Fig. 4 in which the critical masses of plutonium diluted with $\mathrm{SiO}_{2}$ and reflected by $100 \mathrm{~cm}$ of $\mathrm{SiO}_{2}^{\dagger}$

and plutonium diluted with and reflected by $20 \mathrm{~cm}$ of water are presented. The critical mass data for $235 \mathrm{U}$ diluted with and reflected by graphite (Ref. 15) are added for comparison. The numerical data for plutonium- $\mathrm{SiO}_{2}$ are given in Table II.

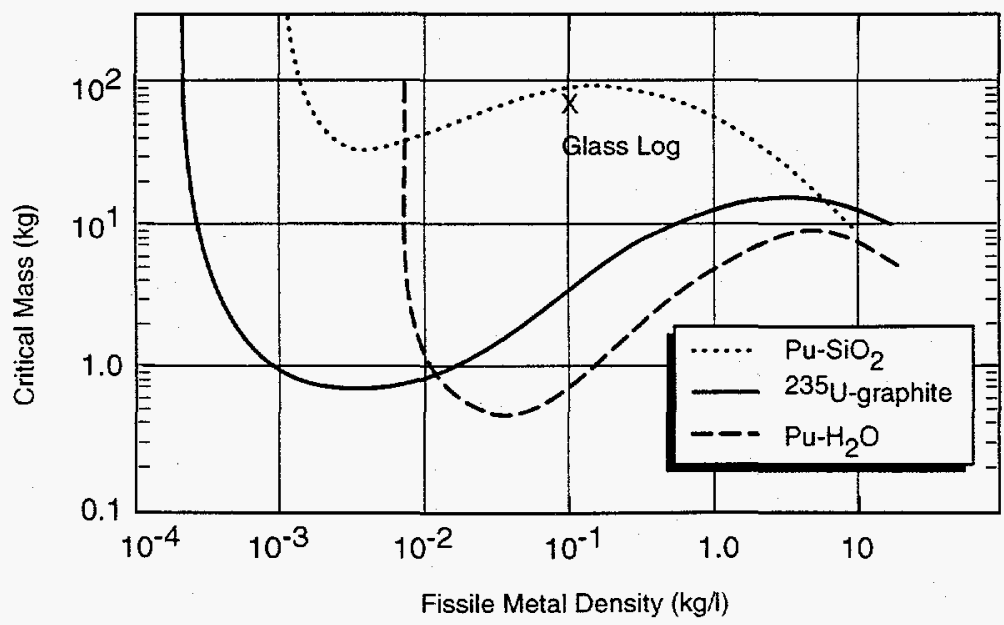

Figure 4. Critical masses of $\mathrm{Pu}-\mathrm{H}_{2} \mathrm{O}$ mixtures reflected by water, $\mathrm{Pu}-\mathrm{SiO}_{2}$ mixtures reflected by $\mathrm{SiO}_{2}$, and ${ }^{235} U$-graphite mixtures reflected by graphite (room temperature). The wide range of the maximum and minimum critical masses and the wide range of the low-density asymptotes are of interest. Each function displays a minimum mass at densities slightly higher than the asymptote. The low-density asymptote in each case is caused by the neutron absorption in the diluent.

\footnotetext{
$\uparrow$ These data, and later $\mathrm{Pu}-\mathrm{H}_{2} \mathrm{O}$-tuff data, are new and were taken for this study.
} 
Table II. ${ }^{239} \mathrm{Pu}$ Metal-SiO 2 Mixtures: Critical Parameters for $\mathrm{SiO}_{2}$-Reflected Spheres at Room Temperature

\begin{tabular}{|l|l|c|c|c|}
\hline $\begin{array}{c}\mathbf{S i}^{239} \mathbf{P u} \\
\text { (Atom ratio) }\end{array}$ & $\begin{array}{c}\text { Density } \\
(\mathbf{k g} / \mathbf{l})\end{array}$ & $\begin{array}{c}\text { Radius } \\
\text { (cm) }\end{array}$ & $\begin{array}{c}\text { Volume } \\
\text { (liters) }\end{array}$ & $\begin{array}{c}\text { Mass } \\
(\mathbf{k g ~ P u})\end{array}$ \\
\hline 0.00 & $1.96 \times 10^{1}$ & 4.02 & $2.71 \times 10^{-1}$ & 5.3 \\
\hline $0.87 \times 10^{0}$ & $1.0 \times 10^{1}$ & 6.17 & $9.86 \times 10^{-1}$ & 9.9 \\
\hline $1.75 \times 10^{0}$ & $5.0 \times 10^{0}$ & 9.75 & $3.88 \times 10^{0}$ & 19.4 \\
\hline $2.75 \times 10^{0}$ & $3.17 \times 10^{0}$ & 12.83 & $8.86 \times 10^{0}$ & 28.1 \\
\hline $4.41 \times 10^{0}$ & $1.98 \times 10^{0}$ & 16.78 & $1.98 \times 10^{1}$ & 39.3 \\
\hline $8.75 \times 10^{0}$ & $1.00 \times 10^{0}$ & 24.12 & $5.88 \times 10^{1}$ & 58.8 \\
\hline $1.47 \times 10^{1}$ & $5.96 \times 10^{-1}$ & 30.97 & $1.25 \times 10^{2}$ & 74.2 \\
\hline $4.72 \times 10^{1}$ & $1.84 \times 10^{-1}$ & 49.74 & $5.15 \times 10^{2}$ & 95.7 \\
\hline $1.836 \times 10^{2}$ & $4.77 \times 10^{-2}$ & 73.98 & $1.70 \times 10^{3}$ & 80.9 \\
\hline $7.528 \times 10^{2}$ & $1.16 \times 10^{-2}$ & 98.95 & $4.06 \times 10^{3}$ & 47.2 \\
\hline $1.175 \times 10^{3}$ & $7.40 \times 10^{-3}$ & 108.26 & $5.32 \times 10^{3}$ & 39.6 \\
\hline $1.578 \times 10^{3}$ & $5.54 \times 10^{-3}$ & 115.80 & $6.51 \times 10^{3}$ & 36.1 \\
\hline $1.839 \times 10^{3}$ & $4.76 \times 10^{-3}$ & 120.77 & $7.38 \times 10^{3}$ & 35.1 \\
\hline $2.812 \times 10^{3}$ & $3.11 \times 10^{-3}$ & 140.93 & $1.17 \times 10^{4}$ & 36.5 \\
\hline $4.376 \times 10^{3}$ & $2.00 \times 10^{-3}$ & 183.81 & $2.60 \times 10^{4}$ & 52.0 \\
\hline $5.513 \times 10^{3}$ & $1.58 \times 10^{-3}$ & 232.47 & $5.26 \times 10^{4}$ & 83.6 \\
\hline $6.783 \times 10^{3}$ & $1.29 \times 10^{-3}$ & 338.17 & $1.62 \times 10^{5}$ & 209.0 \\
\hline $7.351 \times 10^{3}$ & $1.19 \times 10^{-3}$ & 438.21 & $3.53 \times 10^{5}$ & 419.8 \\
\hline $8.019 \times 10^{3}$ & $1.09 \times 10^{-3}$ & 801.25 & $2.15 \times 10^{6}$ & 2352.2 \\
\hline $8.167 \times 10^{3}$ & $1.07 \times 10^{-3}$ & 1095.7 & $5.51 \times 10^{6}$ & 5906.9 \\
\hline
\end{tabular}

The general characteristics of these data are qualitatively similar, but the maximum and minimum critical masses differ by large factors as do the low-density asymptotes caused by water and graphite (a factor of 70). The asymptote is important because its existence is independent of material but its value (in terms of the fissile material density) is very dependent on the material and its density and helps to limit the possibilities of underground critical states for the problem being investigated. The data describing $235 \mathrm{U}$ diluted with graphite are included to illustrate the wide range of criticality possibilities.

For reference below, Fig. 5 presents the critical mass data of plutonium when mixed with and reflected by $100 \mathrm{~cm}$ of $\mathrm{SiO}_{2}$ as a function of the critical volume. This figure is the analog of Fig. 3 for plutonium and water.

No experimental critical data are available to assure the correctness of the calculations for the plutonium- $\mathrm{SiO}_{2}$ system, except for the end point of unreflected plutonium metal. There are no integral tests of the silicon cross sections. In addition, for dry silicon and plutonium mixtures, many fissions take place primarily in the intermediate energy range (between $0.1 \mathrm{eV}$ and $100 \mathrm{keV}$ ), where no integral tests 
for the plutonium fission cross sections exist. Thus, for these dry systems, calculations should be treated with some caution. However, because of the abundance of other experimental critical data for both fast and thermal plutonium systems (Ref. 13), the calculations for these wet plutonium-SiO $\mathrm{S}_{2}$ systems are expected to be reliable. We note that the study is, nevertheless, internally consistent and relative values of critical parameters are reliable. Critical radii, obtained by a different computer program, and cross sections are presented for comparison in the Appendix.

Figure 5. Critical mass of plutonium mixed with and reflected by $\mathrm{SiO}_{2}$ as a function of the critical volume.

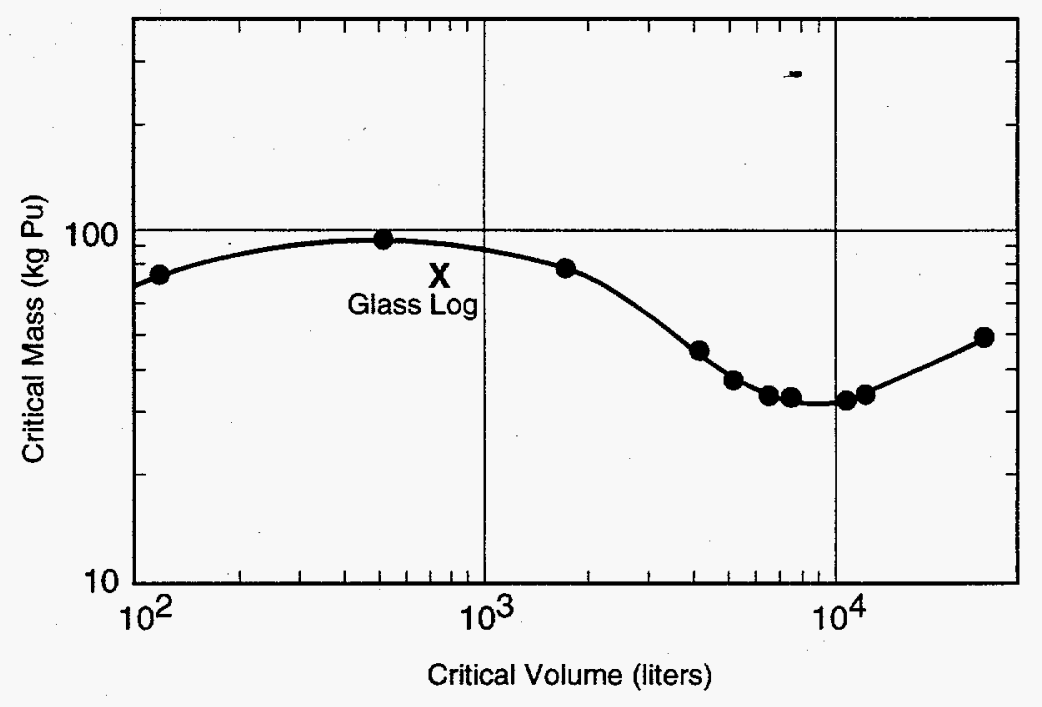

\section{CRITICALITY CALCULATIONS FOR PLUTONIUM-SiO2- ${ }_{2} \mathrm{O},-\mathrm{A}$ THREE-COMPONENT SYSTEM}

In Fig. 6, the reflected critical-mass data for plutonium- $\mathrm{H}_{2} \mathrm{O}$ and plutonium- $\mathrm{SiO}_{2}$ are reproduced from Fig. 4 along with the addition of critical data for plutonium- $\mathrm{SiO}_{2}$ mixtures in which water has been mixed in equal amounts in both the core and $100-\mathrm{cm}$ reflector. The model for adding water assumes that the volume of water added displaces an equal volume of $\mathrm{SiO}_{2}$ and plutonium. For this model, the densities of the plutonium and $\mathrm{SiO}_{2}$ decrease with the addition of water. This is the three-component material postulated in Refs. 1, 2, and 3 that we wish to study in detail. (The plutonium-tuff-water systems will be discussed in Part B. In this latter discussion the displacement model and a "porosity" model will be considered.) The top curve describes dry $\mathrm{Pu}_{-} \mathrm{SiO}_{2}$ mixtures reflected by 100 -cm-thick dry $\mathrm{SiO}_{2}$. The bottom curve is plutonium mixed with and reflected by a $20-\mathrm{cm}$-thick layer of water, while the intermediate curves are $\mathrm{Pu}-\mathrm{SiO}_{2}$ cores mixed with successively greater weight fractions of water and reflected by $100-\mathrm{cm}$-thick $\mathrm{SiO}_{2}$ with the same weight fraction of water. The powerful moderating property of water is evident. The atom ratio of silicon to plutonium for each of the "wet" curves is indicated in Fig. 6 and this same ratio is held constant as more water is added. Thus, in this model, plutonium density decreases steadily as water is added.

For relatively low atom ratios of silicon to plutonium, e.g., 183, 752, and 1570, the initial addition of water decreases the critical mass and critical volume very sharply or one can say that this threecomponent material has significantly greater reactivity. For each ratio of silicon to plutonium, however, a minimum critical mass is reached as water is added, comparable to the minima seen in the two-phase mixtures. For still larger weight fractions of water, the hydrogen in the water becomes a poison (a neutron absorber) and a water (hydrogen) induced asymptote is seen; its location is a unique function of the plutonium density, the atom ratio of silicon to plutonium, and water content. As examples, for $\mathrm{Si} / \mathrm{Pu}=752$ the asymptotic plutonium density is $0.0045 \mathrm{~kg} / \mathrm{l}$; for $\mathrm{Si} / \mathrm{Pu}=2812$, it is $0.0025 \mathrm{~kg} / \mathrm{l}$. For very large $\mathrm{Si} / \mathrm{Pu}$ 
atom ratios, greater than about 6000 , the addition of water (hydrogen) acts invariably as a poison, and the critical mass increases regardless of the amount of water introduced.

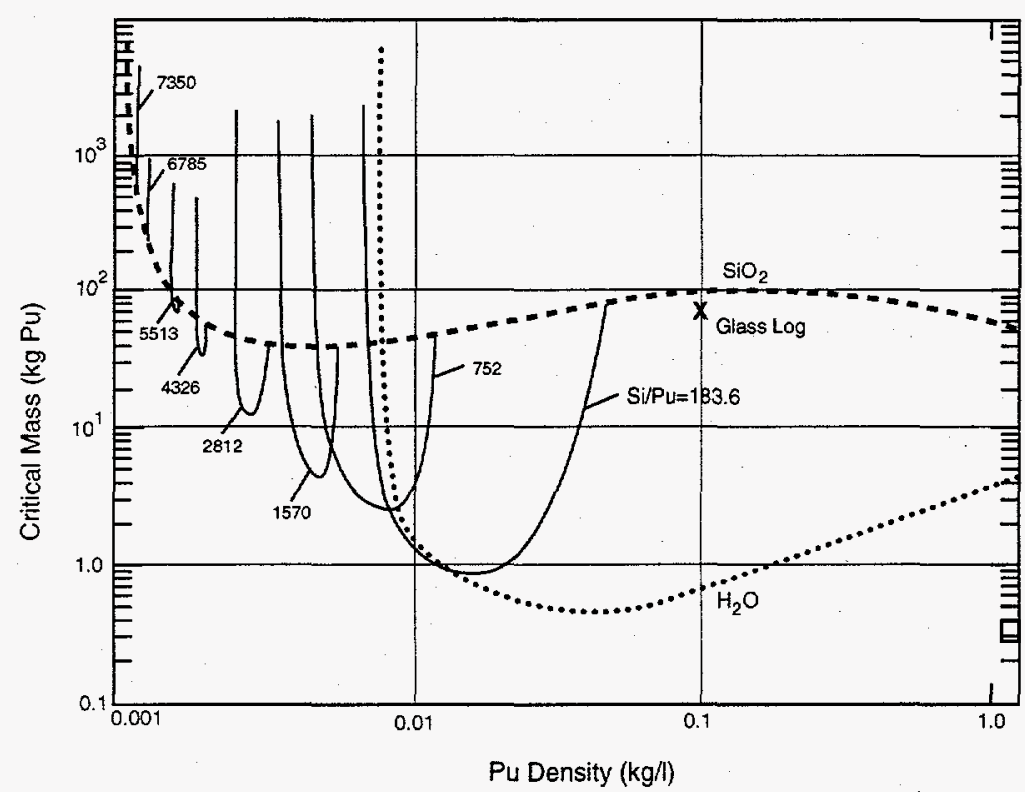

Figure 6. Critical data for mixtures of plutonium, $\mathrm{SiO}_{2}$, and water plotted as a function of plutonium density (room temperature). The upper function is for $\mathrm{Pu}_{\mathrm{SiO}} \mathrm{Si}_{2}$ reproduced from Fig. 4 (and Table II); the lower function is for $\mathrm{Pu}_{\mathrm{u}} \mathrm{H}_{2} \mathrm{O}$ reproduced from Fig. 1 and Table I. The three-component data from Table III illustrate the dramatic effect of the addition of water. Note that the low-density asymptote is different for each Si/Pu atom ratio. These data will be used to establish limits on the configurations of interest.

The complexity of the criticality characteristics of this three-component system can be illustrated by a different scheme of data presentation. In Fig. 7, the critical mass of plutonium is illustrated as a function of the atom ratio of silicon to plutonium. The atom ratio for the asymptote is readily seen. Note that the ordering of the several critical mass functions is reversed between ratios of silicon to plutonium of $10^{3}$ and $10^{4}$. As will be clear later, this is the region of interest for the problem being studied. The data for these mixtures of plutonium, $\mathrm{SiO}_{2}$, and water are listed in Table III. 


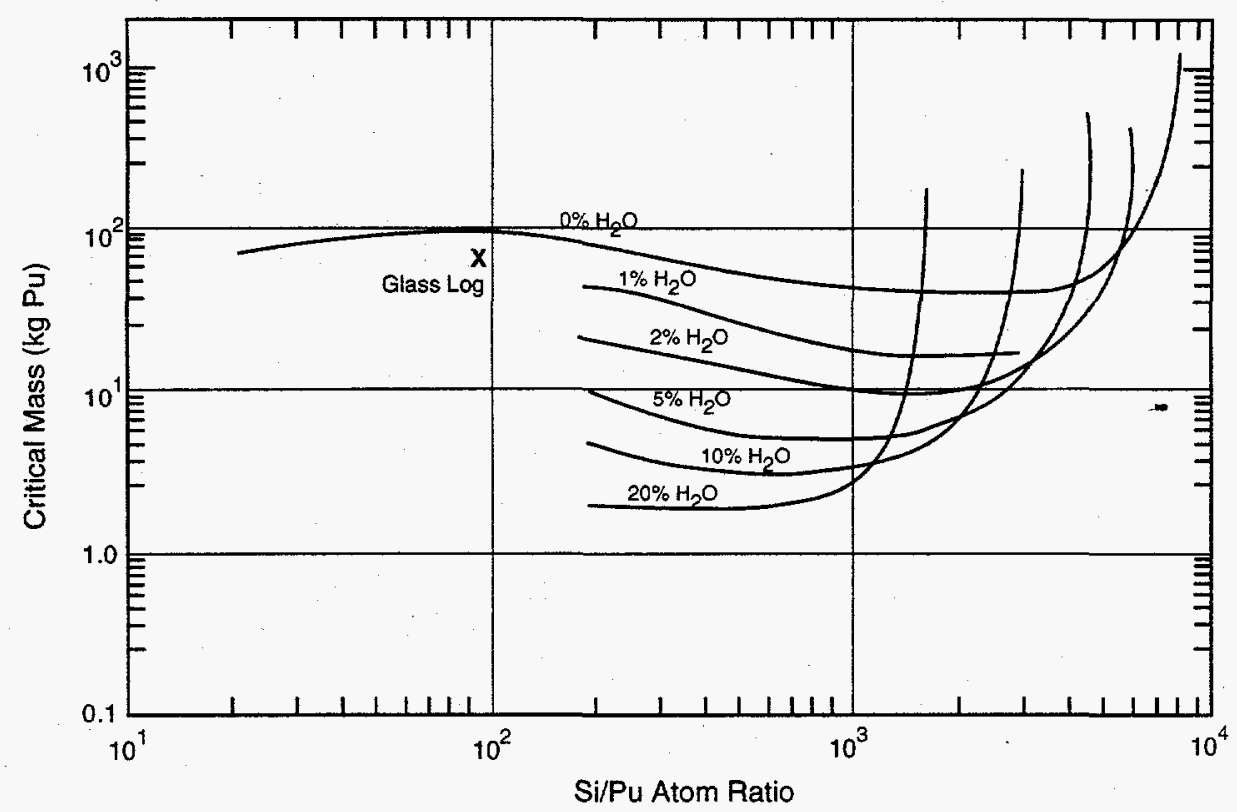

Figure 7. Critical mass of plutonium vs the Si/Pu atom ratio for a few weight percent water in the core and reflector (room temperature). This figure illustrates a part of the complexity of the criticality of three-component systems.

Data similar to these for $\mathrm{Pu}_{-} \mathrm{SiO}_{2}$-water have been obtained elsewhere for mixtures of ${ }^{235} \mathrm{U}$-graphitewater. The general characteristics are similar. See, for example, Refs. 12 and 13.

These data can be examined in another way that is useful in understanding the constraints on the problem at hand. In Figs. 8 and 9, the critical masses of plutonium taken from Figs. 6 and 7 (and Table III) are illustrated as functions of the weight percent of water; the dry critical mass from Fig. 6 (Table III) is the starting point on the left ordinate and water content increases to the right. The critical volume and mass decrease with additional water moderation (except for the very high Si/Pu atom ratios) until a minimum is reached. With additional water content, the critical mass and volume increase until an asymptotic value is achieved. For each $\mathrm{Si} / \mathrm{Pu}$ atom ratio, the weight percent water at the low-plutoniumdensity asymptote is readily seen or can be estimated with reasonable confidence. For example, for $\mathrm{Si} / \mathrm{Pu}=$ 2812 it is $11.2 \%$ and for 5513 it is $3.0 \%$. Thus, for a fixed Si/Pu ratio the water content must be less than the asymptote or criticality cannot occur. Or if the water content is fixed, the possible $\mathrm{Si} / \mathrm{Pu}$ ratio and plutonium mass for criticality are readily seen. 
Table III. ${ }^{239} \mathrm{Pu}-\mathrm{SiO}_{2}+\mathrm{H}_{2} \mathrm{O}$ Mixtures:

Critical Parameters for Spheres Reflected with $\mathrm{SiO}_{2}+\mathrm{H}_{2} \mathrm{O}$ Mixtures at Room Temperature

\begin{tabular}{|c|c|c|c|c|c|}
\hline $\begin{array}{c}\mathbf{S i}^{239} \mathbf{P u} \\
\text { (Atom ratio) }\end{array}$ & $\begin{array}{c}\text { Water } \\
(\mathbf{w t} \%)\end{array}$ & $\begin{array}{c}\text { Density } \\
(\mathrm{kg} / \mathbf{l})\end{array}$ & $\begin{array}{c}\text { Radius } \\
(\mathbf{c m})\end{array}$ & $\begin{array}{c}\text { Volume } \\
\text { (liters) }\end{array}$ & $\begin{array}{c}\text { Mass } \\
(\mathbf{k g ~ P u})\end{array}$ \\
\hline 183 & 0.0 & $4.77 \times 10^{-2}$ & 73.98 & $1.70 \times 10^{3}$ & 80.9 \\
\hline 183 & 2.0 & $4.56 \times 10^{-2}$ & 49.85 & $5.19 \times 10^{2}$ & 23.7 \\
\hline 183 & 5.0 & $4.26 \times 10^{-2}$ & 38.21 & $2.34 \times 10^{2}$ & 10.0 \\
\hline 183 & 10.0 & $3.83 \times 10^{-2}$ & 30.35 & $1.17 \times 10^{2}$ & 4.5 \\
\hline 183 & 20.0 & $3.07 \times 10^{-2}$ & 24.50 & $6.16 \times 10^{1}$ & 1.9 \\
\hline 183 & 30.0 & $2.45 \times 10^{-2}$ & 22.51 & $4.78 \times 10^{1}$ & 1.2 \\
\hline 183 & 40.0 & $1.93 \times 10^{-2}$ & 22.40 & $4.71 \times 10^{1}$ & 0.91 \\
\hline 183 & 50.0 & $1.48 \times 10^{-2}$ & 24.08 & $5.85 \times 10^{1}$ & 0.87 \\
\hline 183 & 60.0 & $1.10 \times 10^{-2}$ & 28.98 & $1.02 \times 10^{2}$ & 1.1 \\
\hline 183 & 70.0 & $7.70 \times 10^{-3}$ & 48.36 & $4.74 \times 10^{2}$ & 3.7 \\
\hline 183 & 75.0 & $6.20 \times 10^{-3}$ & 354.22 & $1.86 \times 10^{5}$ & 1166.8 \\
\hline
\end{tabular}

\begin{tabular}{|c|c|l|l|l|l|}
\hline 752 & 0 & $1.16 \times 10^{-2}$ & 98.95 & $4.06 \times 10^{3}$ & 47.2 \\
\hline 752 & 5.0 & $1.04 \times 10^{-2}$ & 47.93 & $4.61 \times 10^{2}$ & 4.8 \\
\hline 752 & 10.0 & $9.34 \times 10^{-3}$ & 40.92 & $2.87 \times 10^{2}$ & 2.7 \\
\hline 752 & 15.0 & $8.37 \times 10^{-3}$ & 39.21 & $2.52 \times 10^{2}$ & 2.1 \\
\hline 752 & 20.0 & $7.48 \times 10^{-3}$ & 40.27 & $2.73 \times 10^{2}$ & 2.0 \\
\hline 752 & 25.0 & $6.70 \times 10^{-3}$ & 43.71 & $3.50 \times 10^{2}$ & 2.3 \\
\hline 752 & 30.0 & $5.98 \times 10^{-3}$ & 51.46 & $5.71 \times 10^{2}$ & 3.4 \\
\hline 752 & 35.0 & $5.32 \times 10^{-3}$ & 70.62 & $1.48 \times 10^{3}$ & 7.9 \\
\hline 752 & 40.0 & $4.71 \times 10^{-3}$ & 278.99 & $9.10 \times 10^{4}$ & 428.7 \\
\hline
\end{tabular}


Table III. ${ }^{239} \mathrm{Pu}-\mathrm{SiO}_{2}+\mathrm{H}_{2} \mathrm{O}$ Mixtures:

Critical Parameters for Spheres Reflected with $\mathrm{SiO}_{2}+\mathrm{H}_{2} \mathrm{O}$ Mixtures at Room Temperature (continued)

\begin{tabular}{|c|c|c|c|c|c|}
\hline $\begin{array}{c}\mathbf{S i}^{239} \mathbf{P u} \\
\text { (Atom ratio) }\end{array}$ & $\begin{array}{c}\text { Water } \\
(\mathbf{w t} \%)\end{array}$ & $\begin{array}{c}\text { Pu Density } \\
(\mathbf{k g} / \mathbf{l})\end{array}$ & $\begin{array}{c}\text { Radius } \\
(\mathbf{c m})\end{array}$ & $\begin{array}{c}\text { Volume } \\
(\text { liters })\end{array}$ & $\begin{array}{c}\text { Mass } \\
(\mathbf{k g ~ P u})\end{array}$ \\
\hline 1570 & 0.0 & $5.58 \times 10^{-3}$ & 116.82 & $6.68 \times 10^{3}$ & 37.2 \\
\hline 1570 & 1.0 & $5.45 \times 10^{-3}$ & 86.97 & $2.76 \times 10^{3}$ & 15.0 \\
\hline 1570 & 5.0 & $5.00 \times 10^{-3}$ & 63.96 & $1.10 \times 10^{3}$ & 5.5 \\
\hline 1570 & 8.0 & $4.68 \times 10^{-3}$ & 61.76 & $9.87 \times 10^{2}$ & 4.6 \\
\hline 1570 & 10.0 & $4.48 \times 10^{-3}$ & 62.83 & $1.04 \times 10^{3}$ & 4.7 \\
\hline 1570 & 15.0 & $4.02 \times 10^{-3}$ & 74.54 & $1.74 \times 10^{3}$ & 7.0 \\
\hline 1570 & 18.0 & $3.76 \times 10^{-3}$ & 95.74 & $3.68 \times 10^{3}$ & 13.8 \\
\hline 1570 & 20.0 & $3.60 \times 10^{-3}$ & 132.56 & $9.76 \times 10^{3}$ & 35.1 \\
\hline 1570 & 21.0 & $3.52 \times 10^{-3}$ & 182.20 & $2.53 \times 10^{4}$ & 89.2 \\
\hline
\end{tabular}

\begin{tabular}{|l|l|l|l|l|l|}
\hline 2812 & 0.0 & $3.11 \times 10^{-3}$ & 140.93 & $1.17 \times 10^{4}$ & 36.5 \\
\hline 2812 & 1.0 & $3.04 \times 10^{-3}$ & 110.00 & $5.58 \times 10^{3}$ & 16.9 \\
\hline 2812 & 3.0 & $2.91 \times 10^{-3}$ & 96.92 & $3.81 \times 10^{3}$ & 11.1 \\
\hline 2812 & 4.5 & $2.82 \times 10^{-3}$ & 97.76 & $3.91 \times 10^{3}$ & 11.0 \\
\hline 2812 & 5.1 & $2.78 \times 10^{-3}$ & 99.67 & $4.15 \times 10^{3}$ & 11.5 \\
\hline 2812 & 7.0 & $2.67 \times 10^{-3}$ & 112.59 & $5.98 \times 10^{3}$ & 16.0 \\
\hline 2812 & 9.0 & $2.55 \times 10^{-3}$ & 149.50 & $1.40 \times 10^{4}$ & 35.8 \\
\hline 2812 & 10.0 & $2.50 \times 10^{-3}$ & 200.47 & $3.38 \times 10^{4}$ & 84.4 \\
\hline
\end{tabular}

\begin{tabular}{|l|l|l|l|l|l|}
\hline 4376 & 0.0 & $2.00 \times 10^{-3}$ & 183.81 & $2.60 \times 10^{4}$ & 52.0 \\
\hline 4376 & 0.5 & $1.98 \times 10^{-3}$ & 164.23 & $1.86 \times 10^{4}$ & 36.7 \\
\hline 4376 & 1.0 & $1.95 \times 10^{-3}$ & 157.56 & $1.64 \times 10^{4}$ & 32.0 \\
\hline 4376 & 2.0 & $1.91 \times 10^{-3}$ & 159.44 & $1.70 \times 10^{4}$ & 32.5 \\
\hline 4376 & 3.0 & $1.87 \times 10^{-3}$ & 177.99 & $236 \times 10^{4}$ & 44.2 \\
\hline 4376 & 4.0 & $1.83 \times 10^{-3}$ & 227.28 & $4.92 \times 10^{4}$ & 90.1 \\
\hline
\end{tabular}

\begin{tabular}{|c|c|l|l|l|c|}
\hline 5513 & 0.0 & $1.58 \times 10^{-3}$ & 232.47 & $5.26 \times 10^{4}$ & 83.6 \\
\hline 5513 & 0.5 & $1.57 \times 10^{-3}$ & 220.22 & $4.47 \times 10^{4}$ & 70.3 \\
\hline 5513 & 1.0 & $1.55 \times 10^{-3}$ & 226.65 & $4.88 \times 10^{4}$ & 75.6 \\
\hline 5513 & 1.5 & $1.54 \times 10^{-3}$ & 247.87 & $6.38 \times 10^{4}$ & 98.0 \\
\hline 5513 & 2.0 & $1.52 \times 10^{-3}$ & 294.56 & $1.07 \times 10^{5}$ & 162.7 \\
\hline
\end{tabular}


Table III. ${ }^{239} \mathrm{Pu}-\mathrm{SiO}_{2}+\mathrm{H}_{2} \mathrm{O}$ Mixtures:

Critical Parameters for Spheres Reflected with $\mathrm{SiO}_{2}+\mathrm{H}_{2} \mathrm{O}$ Mixtures at Room Temperature (continued)

\begin{tabular}{|c|c|c|c|c|c|}
\hline $\begin{array}{c}\mathrm{Si}^{239} \mathbf{P u} \\
\text { (Atom ratio) }\end{array}$ & $\begin{array}{c}\text { Water } \\
(\mathbf{w t} \%)\end{array}$ & $\begin{array}{c}\text { Pu Density } \\
(\mathbf{k g} / \mathbf{l})\end{array}$ & $\begin{array}{c}\text { Radius } \\
(\mathbf{c m})\end{array}$ & $\begin{array}{c}\text { Volume } \\
(\text { liters })\end{array}$ & $\begin{array}{c}\text { Mass } \\
(\mathbf{k g ~ P u})\end{array}$ \\
\hline 6785 & 0.0 & $1.290 \times 10^{-3}$ & 338.17 & $1.62 \times 10^{5}$ & 209.0 \\
\hline 6785 & 0.10 & $1.287 \times 10^{-3}$ & 340.36 & $1.65 \times 10^{5}$ & 212.6 \\
\hline 6785 & 0.25 & $1.283 \times 10^{-3}$ & 349.56 & $1.79 \times 10^{5}$ & 229.6 \\
\hline 6785 & 0.50 & $1.275 \times 10^{-3}$ & 382.42 & $2.34 \times 10^{5}$ & 302.9 \\
\hline 6785 & 0.60 & $1.272 \times 10^{-3}$ & 404.13 & $2.76 \times 10^{5}$ & 352.0 \\
\hline 6785 & 0.70 & $1.270 \times 10^{-3}$ & 430.96 & $3.35 \times 10^{5}$ & 425.9 \\
\hline
\end{tabular}

\begin{tabular}{|c|c|l|l|l|l|}
\hline 7350 & 0.0 & $1.191 \times 10^{-3}$ & 438.21 & $3.52 \times 10^{5}$ & 419.8 \\
\hline 7350 & 0.10 & $1.188 \times 10^{-3}$ & 457.96 & $4.02 \times 10^{5}$ & 478.0 \\
\hline 7350 & 0.25 & $1.184 \times 10^{-3}$ & 506.19 & $5.43 \times 10^{5}$ & 643.3 \\
\hline 7350 & 0.50 & $1.178 \times 10^{-3}$ & 701.26 & $1.44 \times 10^{6}$ & 1701.4 \\
\hline 7350 & 0.60 & $1.175 \times 10^{-3}$ & 913.38 & $3.19 \times 10^{6}$ & 3751.8 \\
\hline 7350 & 0.70 & $1.173 \times 10^{-3}$ & 1935.6 & $3.04 \times 10^{7}$ & 35620.4 \\
\hline
\end{tabular}



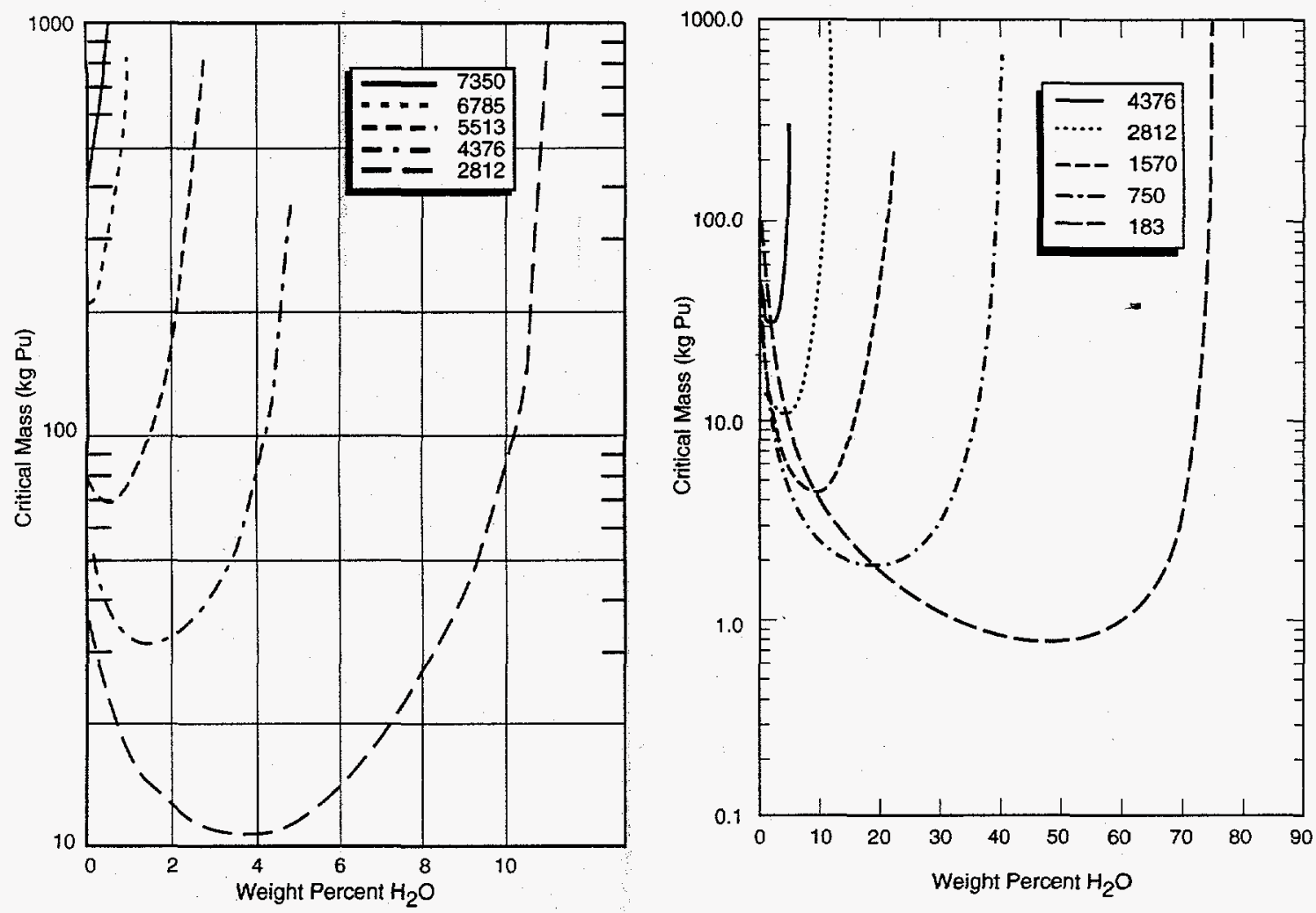

Figures 8 and 9. The critical mass Mc of plutonium as a function of the weight percent of water for various Si/Pu atom ratios (room temperature).These critical mass data are the same as those illustrated in Fig. 6 but shown as a function of the weight percent of water. Note that for each Si/Pu atom ratio, the asymptote establishes an upper limit on the amount of water for the critical state. In addition, for each Si/Pu ratio, the minimum of the function establishes a lower limit to any possible unstable condition. The loci of these two limiting conditions are plotted on Fig. 10.

\section{CONSTRAINTS ON THE POSSIBLE CRITICAL CONFIGURATIONS}

The set of necessary data for mixtures of plutonium, $\mathrm{SiO}_{2}$, and water is now nearly complete, and constraints can be applied that limit the number of cases that need to be examined in more detail. Not all configurations are of interest. To develop these constraints, a few specific cases must be chosen. It is necessary to assume specific details to avoid generalities that cannot be checked. To proceed, we assume $75 \mathrm{~kg}$ of plutonium in a silicon dioxide $\log$ of $50-\mathrm{cm}$ radius and $100-\mathrm{cm}$ length reflected by pure $\mathrm{SiO}_{2}$. The Si/Pu ratio of this log is about 90:1 and the density of plutonium in the log is about $0.1 \mathrm{~kg} / \mathrm{l} . \mathrm{In}$ addition, we must make assumptions relating to the physical and geological situation. These assumptions, postulated in Refs. 1,2, and 3 are accepted for purposes of discussion and calculation, but only for these purposes.

The situations or processes postulated in Refs. 1,2, and 3 involve at least the following:

1. Seventy-five kilograms are to be vitrified into silicate "logs." These logs are to be placed within a massive container and buried in a $\mathrm{SiO}_{2}$ medium. The initial $\mathrm{Si} / \mathrm{Pu}$ ratio for these logs is about 
90:1 and the plutonium density is about $0.1 \mathrm{~kg} / \mathrm{l}$. This $\log$ is identified (by an X) as safely subcritical on Figs. 4, 5, 6, and 7.

2. Over sufficient time, the containment in which this log is placed disintegrates and the plutonium diffuses into a spherical mixture of $\mathrm{Pu}-\mathrm{SiO}_{2}$ with the possibility of some water content.

Three specific scenarios have been postulated. Others are mentioned in Refs. 1, 2, and 3 but are only variations of these three. The scenarios are as follows:

a. The volume of plutonium and $\mathrm{SiO}_{2}$, initially subcritical, slowly expands and mixes with more $\mathrm{SiO}_{2}$, eventually reaching a critical state and finally a supercritical state caused by the increased moderation of $\mathrm{SiO}_{2}$. This is the "dry" scenario.

b. The $\mathrm{SiO}_{2}$ "log" cracks or disintegrates and water enters the region containing plutonium. The amount of $\mathrm{SiO}_{2}$ mixed with the original log may or may not have increased. This is one "wet" scenario: water moves into the volume containing plutonium.

c. The plutonium and $\mathrm{SiO} 2$ separate (Ref. 2 postulates that some or all of the $\mathrm{SiO} 2$ dissolves and moves elsewhere), and the plutonium remains behind in the form of particles that are free to move. These particles then slowly move into a stratum of $\mathrm{SiO} 2$ that has some water. The plutonium may exist as a dry powder, most likely $\mathrm{PuO} 2$, or may be mixed with water, or carry some silicon with it. This is another "wet" scenario during which plutonium moves into a wet stratum.

\section{Discussion of Postulates}

a. The Dry Scenario-Expansion of the initial volume of dry $\mathrm{SiO}_{2}$ mixture into more dry $\mathrm{SiO}_{2}$. By referring to Fig. $5, M_{C}(\mathrm{Pu})$ vs $V_{c}$, the initial mass of $75 \mathrm{~kg}$ in a $\mathrm{Pu}-\mathrm{SiO}_{2} \log$ (now taken to be a sphere) is identified at an initial volume of 7851 . If the mixing and expansion should take place as postulated, a critical state for the $75 \mathrm{~kg}$ could be achieved at a volume of about 20001 . Reference 1 further assumes that this expansion would increase to the maximum supercriticality state at a volume of about $9000 \mathrm{l}$ (where the critical mass is only $34 \mathrm{~kg}$ ) before a neutron chain reaction would begin. No mechanism for this phenomenon is known, and it is considered in these papers only to show that even these assumptions would not lead to an autocatalytic state with the potential for an explosion. Reference 1 argues that the time scale for these actions may be geologic; later references (Refs. 2 and 3) add possibilities that take place on a much faster time scale: a millisecond expansion of $\mathrm{PuO}_{2}$ vapor through solid tuff at molecular velocities. This hypothesis is nonphysical. Even if the $\mathrm{PuO}_{2}$ could be preferentially heated to high temperatures, the mean free path for collisions with $\mathrm{SiO}_{2}$ molecules is very, very short. At this stage of examination, and accepting the assumptions in Refs. 1, 2, and 3, a critical state is possible, but a supercritical state or autocatalytic state or both is impossible. "The dry scenario is re-examined again in Part B for the plutonium-tuff mixtures.

b. The Wet Scenario-Mixing of the water with the $\mathrm{Pu} / \mathrm{SiO}_{2}$ mixture, either with or without mixing with more $\mathrm{SiO}_{2}$. Should sufficient water mix with the $75 \mathrm{~kg}$ mass at some volume below the $20001 \mathrm{dry}-$ critical-level case, the effect could be to create a small, low-power critical system or reactor. This scenario is the plutonium analog to the Oklo "reactor" of two billion years ago (Ref. 4) as recognized in Refs. 1,2, and 3. The fission power could vary widely, given sufficient freedom of postulates. The behavior of such a system is controlled primarily by the flow rate of the water, which is reported to be extremely slow through tuff (Ref. 16). Too much water or too little water would stop the reaction. It is difficult to achieve significantly higher reactivities than delayed-critical on geologic time scales (or any time scale) because

\footnotetext{
* Nevertheless, the calculational assumptions relating to the expansion of plutonium at hot molecular velocities half a meter or more into surrounding solid $\mathrm{SiO} 2$, are examined in a companion paper.
} 
these higher reactivities lead to higher powers, higher temperatures, and evaporation of the water. No explosion would be expected because the $\mathrm{Pu}-\mathrm{SiO}_{2}-\mathrm{H}_{2} \mathrm{O}$ system would have sufficient time to adjust to the addition of water by removing water through boiling. This is a self-regulating process.

c. The Movement of Plutonium into a Wet Stratum-The movement of dry or damp plutonium, or PuO2, with or without $\mathrm{SiO} 2$, into a stratum containing an arbitrary amount of water. This case is more complicated and requires very careful examination because it is the only scenario so far identified (and believed to be unique) that could lead to an unstable or possibly autocatalytic power transient. In effect, the assumption states that a set of cracks (equivalent to drill holes) exists, which could allow plutonium particles to slowly penetrate a wet stratum, creating what is assumed to be a uniform mixture of the three components. The possible critical states of this three-component mixture have been illustrated in Figs. 6 , 7,8 , and 9.

One constraint on the critical configurations that needs to be examined is the water-poisoning asymptote (Figs. 8 and 9) for each Si/Pu ratio. For example, if the water concentration is more than $3 \mathrm{wt} \%$, criticality is not possible for ratios of silicon to plutonium greater than 5513, regardless of how much plutonium is involved. As another example, for a Si/Pu ratio of 1570 , no criticality is possible for a water concentration greater than $21 \mathrm{wt} \%$. This constraint, based on the water-induced asymptote, is illustrated in Fig. 10; for a given $\mathrm{Si} / \mathrm{Pu}$ ratio, the water content must be less than the uppermost line on the figure for criticality to be achieved. For some mixtures of plutonium, $\mathrm{SiO}_{2}$, and water, a configuration that is found just on or very near this line on Fig. 10 can be unstable and possibly could be "autocatalytic," i.e., if water leaves the system and the volume does not change, the system reactivity and fission power could increase.

A second constraint is found by further examination of the functions in Fig. 8. Examples make this easier. Referring to Fig. 8, Table III, and the $\mathrm{Si} / \mathrm{Pu}$ ratio of 5513, the dry critical mass is about $84 \mathrm{~kg}$. The minimum of this function is about $70 \mathrm{~kg}$ at $0.5 \mathrm{wt} \%$ water. At higher concentrations of water, the critical mass increases continuously up to the asymptote corresponding to about $3 \mathrm{wt} \%$ water. Between $0.5 \mathrm{wt} \%$ and $3 \mathrm{wt} \%$ water, an unstable or possibly autocatalytic region exists. Autocatalysis is impossible between $0.0 \mathrm{wt} \%$ and $0.5 \mathrm{wt} \%$ water; autocatalysis is possible only between $0.5 \mathrm{wt} \%$ and $3.0 \mathrm{wt} \%$. On the same figure, for a Si/Pu ratio of 2812 , the unstable region exists only between $4.0 \mathrm{wt} \%$ and $11.2 \mathrm{wt} \%$ water. The minimum of each of these Si/Pu critical functions is plotted on Fig. 10 as the lower curve. The unstable or possibly autocatalytic region lies only between these two curves on Fig. 10. The lower limit function is modest; it represents the water content for no instability. A somewhat higher water content would be barely autocatalytic and trivial in results.

A third constraint is, of course, the available mass of plutonium, which has been taken to be $75 \mathrm{~kg}$. If this amount is assumed to move into a wet stratum of $\mathrm{SiO}_{2}$, the $\mathrm{Si} / \mathrm{Pu}$ ratio will slowly decrease. The following examples are instructive. If the water content were, e.g., $0.5 \%$ by weight (see Fig. 8 ), criticality is possible for Si/Pu atom ratios of 7350 or 6785 , but the required masses are $1000 \mathrm{~kg}$ and $300 \mathrm{~kg}$, respectively; only $75 \mathrm{~kg}$ are available. If the water concentration were $1.0 \mathrm{wt} \%, 75 \mathrm{~kg}$ could be critical at a Si/Pu ratio of 5513. Proceeding to lower Si/Pu ratios at $75 \mathrm{~kg}$ on Fig. 8, this mass could be critical for 4.0 wt $\%$ water at $\mathrm{Si} / \mathrm{Pu}=4376$ and for $10.0 \%$ at $\mathrm{Si} / \mathrm{Pu}=2812$. The locus of these points is plotted on Fig. 10 as the middle function. The region of autocatalysis is now restricted to the region between the lowest and the middle function of Fig. 10.

The final constraint to be discussed in this section is the assumed amount of water in the $\mathrm{SiO}_{2}$ surrounding the $\mathrm{Pu}-\mathrm{SiO}_{2}$ mixture. The only guidelines on water content of the soil or rock are the actual measurements and analyses by geologists. A reasonable upper limit is $5 \%$ by weight (Ref. 5). Both 
$5.0 \mathrm{wt} \%$ and $10.0 \mathrm{wt} \%$ water content will be examined to be conservative. These constraints are illustrated by vertical lines on Fig. 10 .

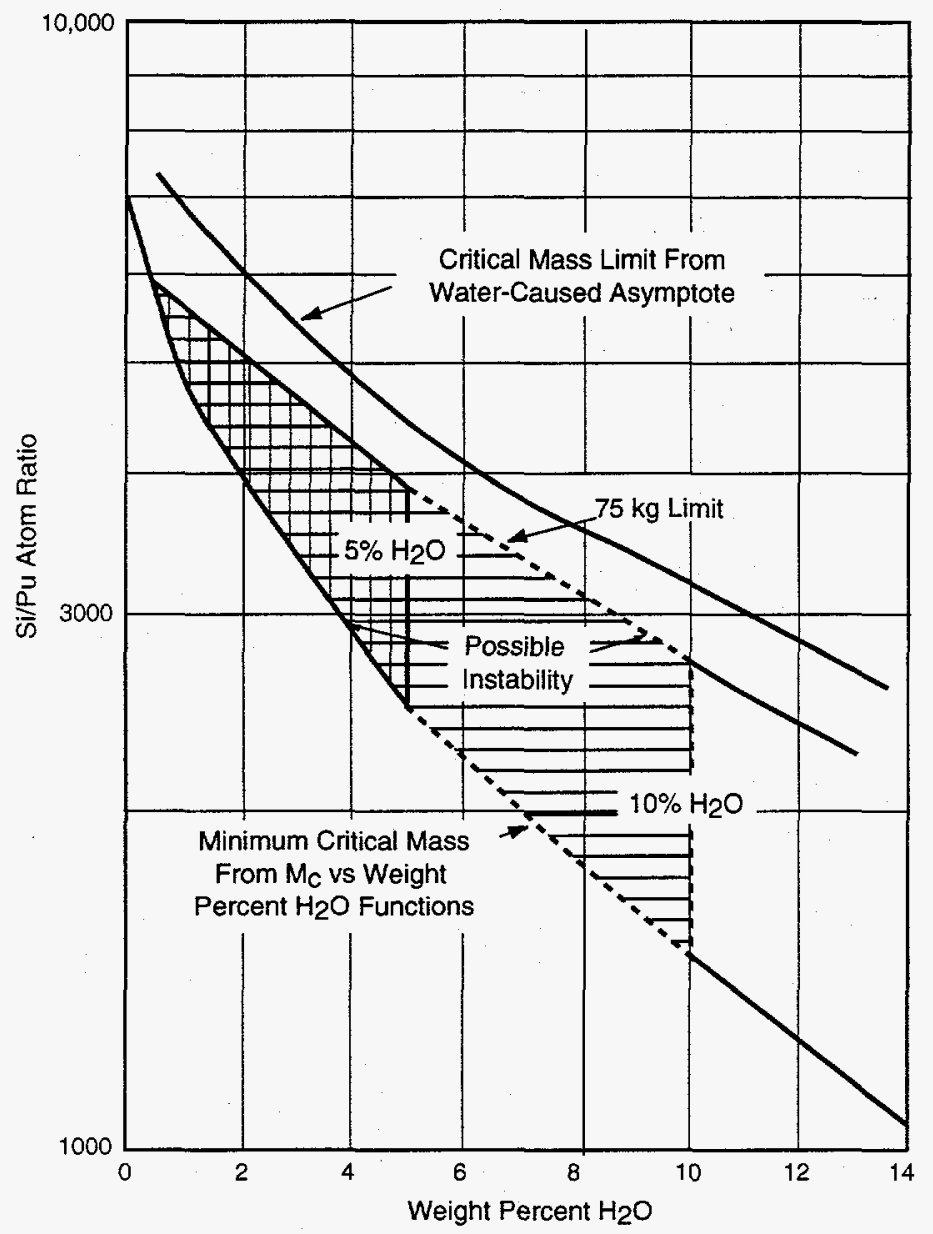

Figure 10. Limiting values of water content as a function of Si/Pu ratio (room temperature). The limiting loci described for each Si/Pu ratio in the caption for Figs. 8 and 9 are illustrated as the top and bottom lines. The intermediate line reflects the limit of $75 \mathrm{~kg}$ of plutonium and is also derived from Figs. 8 and 9. Vertical lines are drawn at 5 and $10 \mathrm{wt} \%$ water to show the limit based on the accepted maximum water content and twice this amount. The region within the triangular areas represents the only region of possible autocatalytic behavior.

The full picture of all these constraints can be seen on Fig. 10 as triangles shaded on the semi-log plot. The defining corners for $75 \mathrm{~kg}$ and $5 \mathrm{wt} \%$ water are as follows: $\mathrm{Si} / \mathrm{Pu}=5800, \% \mathrm{H}_{2} \mathrm{O}=0.5 ; \mathrm{Si} / \mathrm{Pu}=$ $3900, \% \mathrm{H}_{2} \mathrm{O}=5.0 ; \mathrm{Si} / \mathrm{Pu}=2400, \% \mathrm{H}_{2} \mathrm{O}=5$. If the limiting amount of water is $10.0 \%$, the defining points on Fig. 10 are 5800 and $0.5 \mathrm{wt} \%, 2800$ and $10.0 \mathrm{wt} \%$, and 1600 and $10.0 \mathrm{wt} \%$. Configurations with compositions outside these limits are of no interest for the reasons just developed.

A question can be raised for a special class of configurations such as the following. Assume, for example, that plutonium penetrates into a moist layer of rock containing $6 \mathrm{wt} \%$ water and the penetration is sufficient to achieve a total of $75 \mathrm{~kg}$ in the appropriate spherical volume (see Fig. 8). No criticality is possible at $\mathrm{Si} / \mathrm{Pu}=4376$ because of too much water. However, if the climate of the region should enter a drying phase, the water content could be reduced to $3.8 \mathrm{wt} \%$ and the system could become critical, unstable, and possibly autocatalytic, but the constraints discussed above would remain operative.

The appropriate constraints on plutonium and water concentration have been defined and the (now more limited) possibilities for supercritical configurations will be considered. This case, the movement of plutonium into a wet stratum, raises the possibility of unstable configurations and the possibility of an autocatalytic reactivity power transient. This is the situation of most interest. 


\section{REACTIVITY $\left(\boldsymbol{k}_{\text {eff }}\right)$ CALCULATIONS}

The previous section defined the possibilities for critical conditions, given certain constraints. This section will examine the possibilities for supercritical configurations that might be created and developed as a result of the movement and mixing of plutonium, silicon, and water. As an example, if a critical state is achieved at a water concentration of $4.0 \mathrm{wt} \%$, at a plutonium mass of $90.1 \mathrm{~kg}$ (ignoring for the moment the mass-loading limit of $75 \mathrm{~kg}$ for each $\mathrm{log}$ ), and at a Si/Pu ratio of 4376 (see Fig. 8 and Table III), the resulting fission power could heat the volume and transport water out of the volume, thus reducing the weight percent of water and increasing the reactivity of the mixture. Note that this process does not change the volume or the mass of plutonium so that this change in composition does not follow the critical mass function of $\mathrm{Si} / \mathrm{Pu}=4376$ in Fig. 8; this process has become supercritical. This process could continue and reactivity could rise, increasing the reaction rate. Reference 3 postulates that this autocatalytic process will result in an explosion of "hundreds of tons of TNT equivalent." The criticality aspects of the unstable regions defined above will be examined, quantitatively, in this section, and the postulated explosion aspects will be examined in Part B (for tuff) and in the companion papers on dynamics.

Given the initial assumptions of Refs. 1,2, and 3, the critical state, i.e., a self-sustaining neutron chain reaction, is not impossible; thus the magnitudes of the possible reactivity and power transients must be examined.

The first step in the analysis of a postulated criticality event is to examine the magnitude of the neutron multiplication factor, often referred to as $k_{\text {eff. }}$. This has been done for several functions (with different $\mathrm{Si} / \mathrm{Pu}$ ratios) for the appropriate amounts of water and for several different masses of plutonium. Typical results are illustrated in Fig. 11 (Table IV) for two cases in which the $k_{\text {eff }}$ is plotted against water content for different $\mathrm{Si} / \mathrm{Pu}$ atom ratios and plutonium masses. For example, $90.1 \mathrm{~kg}$ of plutonium with $\mathrm{Si} / \mathrm{Pu}=4376$ is just critical with $4 \mathrm{wt} \%$ water. As the water content is decreased and the mass of plutonium and volume remain constant, the $k_{\text {eff }}$ rises to a maximum of 1.071 , where the water content is $1.06 \mathrm{wt} \% ; k_{\text {eff }}$ drops to 1.031 for the dry case. The same Si/Pu ratio with a fissile mass of $32.5 \mathrm{~kg}$ is just critical with 2 wt $\%$ water. In this case the $k_{\text {eff }}$ decreases monotonically to 0.902 as the water content is reduced.

A second set of examples is illustrated on Fig. 12. The $\mathrm{Si} / \mathrm{Pu}$ ratio is 2812 , the plutonium masses and water contents are $84.4 \mathrm{~kg}$ and $10 \mathrm{wt} \%, 35.8 \mathrm{~kg}$ and $9.0 \mathrm{wt} \%$, and $16.0 \mathrm{~kg}$ and $7.0 \mathrm{wt} \%$. The data for these functions are taken from Table IV. The starting point $\left(k_{\mathrm{eff}}=1.000\right)$ can be identified on Fig. 8 and in the tables. In this case the largest mass could reach a $k_{\text {eff }}$ of 1.178 and remain supercritical even when dry. Each of the lesser plutonium masses is subcritical when dry and the maximum $k_{\text {eff }}$ is lower.

These data show that calculated neutron multiplication factors for some cases range up to about 1.18. Other (not illustrated) data show excess reactivities up to 1.3, but these are not considered because the plutonium mass or soil water content is outside the constraints given above. Some of these reactivity functions have the appearance of being very large and significant. Others are much less significant. It is not obvious that all examples need to be examined in detail. The intent is to pick those that are reasonably typical or are approaching what might be a severe case. Cases showing the possibility of supercriticality and an autocatalytic power response will be examined quantitatively in the following Part B for tuff and in a companion paper on dynamics. 


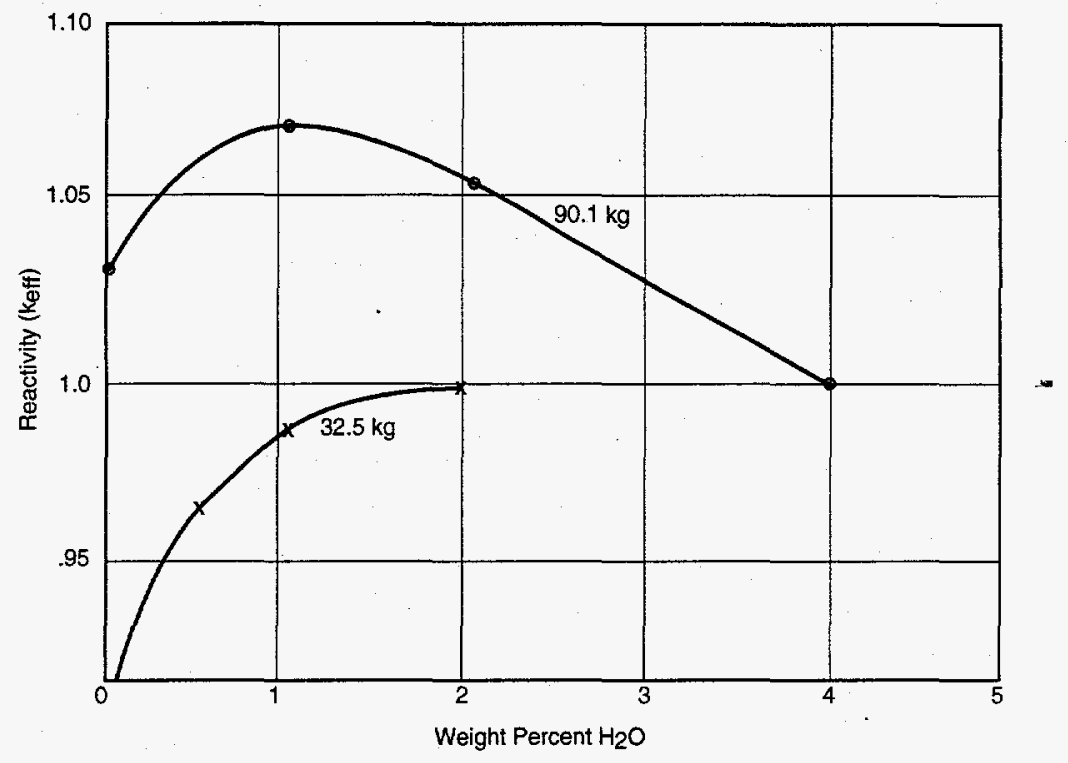

Figure 11. Plot of keff vs water content for several Si/Pu ratios (room temperature). The reactivity (keff) is for two plutonium masses of $90.1 \mathrm{~kg}$ and $32.5 \mathrm{~kg}$, each taken from the critical mass curve in Fig. 8 with Si/Pu=4376. The critical point $(90.13 \mathrm{~kg}$ or $32.49 \mathrm{~kg})$ is taken from the function in Fig. 8 and keff is calculated by step-wise removal of the water. The upper function (for $90.1 \mathrm{~kg}$ ) exhibits autocatalytic behavior as water evaporates and leaves the system. The mass, however, is above the allowed limit. The lower curve $(32.5 \mathrm{~kg})$ is taken from Fig. 8 at a point first expected to show the same instability. However, as water content decreases, the reactivity steadily decreases.

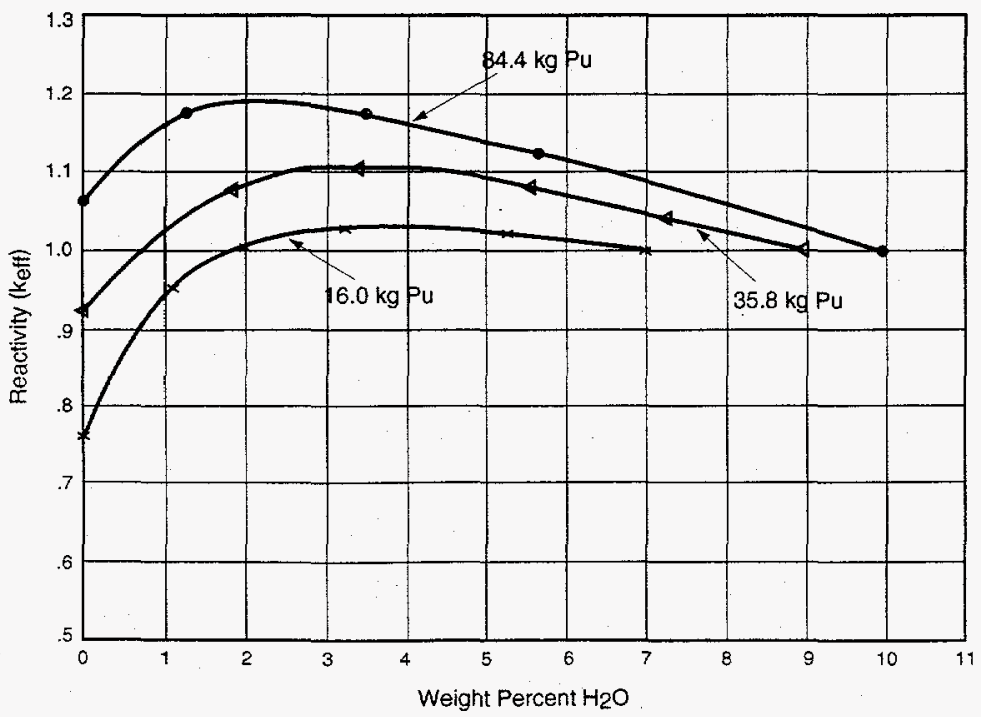

Figure 12. Reactivity ( $\left.k_{\text {eff }}\right)$ for three plutonium masses, each taken from the critical mass curve in Fig. 8 with $\mathrm{Si} / \mathrm{Pu}=2812$ (room temperature). In this case, each of the $k_{\text {eff }}$ functions would be unstable and autocatalytic. The one for $84.4 \mathrm{~kg}$ is outside the $75 \mathrm{~kg}$ limit of Fig. 10, but the other two satisfy the constraints. 
Table IV. 239Pu-SiO2+H2O Reflected Spheres:

Reactivity (keff) For Several Si/239Pu Ratios, Masses of Plutonium, and Water Contents at Room Temperature

A. $\mathrm{Si}^{239} \mathrm{Pu}=183$

Mass $\mathrm{Pu}=3.7 \mathrm{~kg}$

Density $\mathrm{Pu}=7.70 \times 10^{-3} \mathrm{~kg} / \mathrm{l}$

Volume $=474$ liters

\begin{tabular}{|c|c|}
\hline $\begin{array}{c}\text { \% Water } \\
\text { by wt }\end{array}$ & $\boldsymbol{k}_{\text {eff }}$ \\
\hline 70 & 1.00 \\
\hline 65 & 1.040 \\
\hline 49 & 1.028 \\
\hline 34 & 0.825 \\
\hline 0.0 & 0.008 \\
\hline
\end{tabular}

B. $\quad \mathrm{Si}^{239} \mathrm{Pu}=752$

Mass $\mathrm{Pu}=7.9 \mathrm{~kg}$

Density $\mathrm{Pu}=5.30 \times 10^{-3} \mathrm{~kg} / \mathrm{l}$

Volume $=1.476 \times 10^{3}$ liters

\begin{tabular}{|l|l|}
\hline $\begin{array}{c}\text { \% Water } \\
\text { by wt }\end{array}$ & $\boldsymbol{k}_{\text {eff }}$ \\
\hline 35 & 1.000 \\
\hline 25 & 1.081 \\
\hline 16.25 & 1.080 \\
\hline 0.0 & 0.220 \\
\hline
\end{tabular}

C. $\mathrm{Si}^{239} \mathrm{Pu}=1570$

Mass $\mathrm{Pu}=35.1 \mathrm{~kg}$

Density $\mathrm{Pu}=3.60 \times 10^{-3} \mathrm{~kg} / 1$

Volume $=9.76 \times 10^{3}$ liters

\begin{tabular}{|l|l|}
\hline $\begin{array}{c}\text { \% Water } \\
\text { by wt }\end{array}$ & $\boldsymbol{k}_{\text {eff }}$ \\
\hline 20.0 & 1.000 \\
\hline 16.42 & 1.068 \\
\hline 12.12 & 1.143 \\
\hline 6.79 & 1.199 \\
\hline 0.0 & 0.779 \\
\hline
\end{tabular}

D. $\quad \mathrm{Si}^{239} \mathrm{Pu}=\mathbf{1 5 7 0}$

Mass $\mathrm{Pu}=89.2 \mathrm{~kg}$

Density $\mathrm{Pu}=3.52 \times 10^{-3} \mathrm{~kg} / 1$

Volume $=2.53 \times 10^{4}$ liters

\begin{tabular}{|c|c|}
\hline $\begin{array}{c}\text { \% Water } \\
\text { by wt }\end{array}$ & $\boldsymbol{-}_{\text {eff }}$ \\
\hline 21.00 & 1.000 \\
\hline 20.31 & 1.014 \\
\hline 14.58 & 1.137 \\
\hline 12.36 & 1.184 \\
\hline 6.94 & 1.278 \\
\hline 0.0 & 0.982 \\
\hline
\end{tabular}

E. $\mathrm{Si}^{239} \mathrm{Pu}=2812$

Mass $\mathrm{Pu}=16.0 \mathrm{~kg}$

Density $\mathrm{Pu}=2.67 \times 10^{-3} \mathrm{~kg} / \mathrm{l}$

Volume $=5.98 \times 10^{3}$ liters

\begin{tabular}{|l|l|}
\hline $\begin{array}{c}\text { \% Water } \\
\text { by wt }\end{array}$ & $\boldsymbol{k}_{\text {eff }}$ \\
\hline 7.00 & 1.000 \\
\hline 5.30 & 1.023 \\
\hline 3.26 & 1.029 \\
\hline 1.14 & 0.955 \\
\hline 0.0 & 0.773 \\
\hline
\end{tabular}

F. $\quad \mathrm{Si}^{239} \mathrm{Pu}=2812$

Mass $\mathrm{Pu}=35.8 \mathrm{~kg}$

Density $\mathrm{Pu}=2.55 \times 10^{-3} \mathrm{~kg} / 1$

Volume $=1.40 \times 10^{4}$ liters

\begin{tabular}{|l|l|}
\hline $\begin{array}{c}\text { \% Water } \\
\text { by wt }\end{array}$ & $\boldsymbol{k}_{\text {eff }}$ \\
\hline 9.00 & 1.000 \\
\hline 7.28 & 1.041 \\
\hline 5.52 & 1.079 \\
\hline 3.40 & 1.109 \\
\hline 1.19 & 1.075 \\
\hline 0.0 & 0.922 \\
\hline
\end{tabular}


Table IV. ${ }^{239} \mathrm{Pu}-\mathrm{SiO}_{2}+\mathrm{H}_{2} \mathrm{O}$ Reflected Spheres

Reactivity $\left(k_{\mathrm{eff}}\right)$ For Several Si ${ }^{239}$ Pu Ratios, Masses of Plutonium, and Water Contents at Room Temperature (continued)

G. $\quad \mathrm{Si}^{239} \mathrm{Pu}=\mathbf{2 8 1 2}$

Mass $\mathrm{Pu}=84.4 \mathrm{~kg}$

Density $\mathrm{Pu}=2.50 \times 10^{-3} \mathrm{~kg} / 1$

Volume $=3.38 \times 10^{4}$ liters

\begin{tabular}{|c|c|}
\hline $\begin{array}{c}\text { \% Water } \\
\text { by wt }\end{array}$ & $\boldsymbol{k}_{\text {eff }}$ \\
\hline 10 & 1.000 \\
\hline 5.64 & 1.122 \\
\hline 3.47 & 1.173 \\
\hline 1.21 & 1.178 \\
\hline 0.0 & 1.066 \\
\hline
\end{tabular}

H. $\quad \mathrm{Si}^{239} \mathrm{Pu}=4376$

Mass $\mathrm{Pu}=32.5 \mathrm{~kg}$

Density $\mathrm{Pu}=1.913 \times 10^{-3} \mathrm{~kg} / 1$

Volume $=1.70 \times 10^{4}$ liters

\begin{tabular}{|l|l|}
\hline $\begin{array}{c}\text { \% Water } \\
\text { by wt }\end{array}$ & $\boldsymbol{k}_{\text {eff }}$ \\
\hline 2.0 & 1.000 \\
\hline 1.01 & 0.988 \\
\hline 0.51 & 0.962 \\
\hline 0.0 & 0.902 \\
\hline
\end{tabular}

I. $\mathrm{Si}^{239} \mathrm{Pu}=4376$

Mass $\mathrm{Pu}=90.1 \mathrm{~kg}$

Density $\mathrm{Pu}=1.832 \times 10^{-3} \mathrm{~kg} / \mathrm{l}$

Volume $=4.92 \times 10^{4}$ liters

\begin{tabular}{|l|l|}
\hline $\begin{array}{c}\text { \% Water } \\
\text { by wt }\end{array}$ & $\boldsymbol{k}_{\text {eff }}$ \\
\hline 4.000 & 1.000 \\
\hline 3.060 & 1.024 \\
\hline 2.085 & 1.053 \\
\hline 1.060 & 1.071 \\
\hline 0.0 & 1.031 \\
\hline
\end{tabular}

J. $\quad \mathrm{Si}^{239} \mathrm{Pu}=\mathbf{5 5 1 3}$

Mass $\mathrm{Pu}=162.7 \mathrm{~kg}$

Density $\mathrm{Pu}=1.519 \times 10^{-3} \mathrm{~kg} / 1$

Volume $=1.07 \times 10^{5}$ liters

\begin{tabular}{|l|l|}
\hline $\begin{array}{c}\text { \% Water } \\
\text { by wt }\end{array}$ & $\boldsymbol{k}_{\text {eff }}$ \\
\hline 2.0 & 1.000 \\
\hline 1.039 & 1.039 \\
\hline 0.516 & 1.052 \\
\hline 0.0 & 1.049 \\
\hline
\end{tabular}

\section{PART B: CRITICALITY CALCULATIONS PLUTONIUM, TUFF, AND WATER}

\section{NUCLEAR CRITICALITY, PLUTONIUM-TUFF}

The tuff composition used in these calculations is taken from Ref. 6 and differs from $\mathrm{SiO}_{2}$ in that the $\mathrm{SiO}_{2}$ content is only $77 \%$ by weight with the difference made up primarily by oxides of aluminum, potassium, and sodium, for example, with a number of minor constituents, some of which are neutron poisons. The composition is given in Ref. 6 and reproduced in the Appendix. The treatment of the Putuff- $\mathrm{H}_{2} \mathrm{O}$ data parallels the treatment of the $\mathrm{Pu}-\mathrm{SiO}_{2}-\mathrm{H}_{2} \mathrm{O}$ data with the addition of pertinent comparisons. To allow easy comparison between $\mathrm{Pu}-\mathrm{SiO}_{2}$ data and $\mathrm{Pu}$-tuff data, the $\mathrm{Si} / \mathrm{Pu}$ ratio for tuff is multiplied by $1 / 0.77$ and denoted by $\mathrm{Si} / \mathrm{Pu}^{*}$; densities are comparable.

In Fig. 13 (Table V) the calculated reflected critical masses for plutonium mixed with Nevada tuff are shown as a function of the plutonium density along with the comparable critical masses for plutonium mixed with pure $\mathrm{SiO}_{2}$. The latter data are reproduced from Fig. 4. The model used for mixing the plutonium with tuff is the volume displacement model discussed earlier, i.e., the volume occupied by the 
plutonium displaces a comparable volume of tuff. Significant differences can be noticed immediately. (1) The low-density asymptote is increased from 0.001 to $0.003 \mathrm{~g} / \mathrm{cm}^{3}$. Thus, the number of highly diluted cases requiring consideration is further restricted. (2) The moderating/absorbing effects of $\mathrm{SiO}_{2}$ that decrease the critical mass from $95.7 \mathrm{~kg}$ at a plutonium density of $0.184 \mathrm{~kg} / \mathrm{l}$ to $35.1 \mathrm{~kg}$ at a density of $0.0048 \mathrm{~kg} / 1$ (seen in Fig. 13) very nearly disappear when the diluent has the composition of tuff. With tuff as a diluent, the maximum and minimum critical masses are $112.6 \mathrm{~kg}$ and $85.6 \mathrm{~kg}$; the ratio of the maximum and minimum critical masses in the region of this dip in the critical mass functions drops from 2.7 to 1.3. The potential for the postulated dry autocatalytic behavior (as postulated in Refs. 1 and 2) depends on the presence of this "dip." Substantial reduction in the magnitude of the "dip" constrains the conditions that must be met to achieve autocatalytic behavior. This increased minimum mass when Nevada tuff is the diluent eliminates the need to consider the "dry critical" problem that was postulated in Ref. 1 and in Section V of this paper; $75 \mathrm{~kg}$ would never become critical in dry tuff. Including the ${ }^{240} \mathrm{Pu}$ or allowing for decay of ${ }^{239} \mathrm{Pu}$ to ${ }^{235} \mathrm{U}$ would increase the critical masses even more.

Figure 14 illustrates the data of Table $\mathrm{V}$ in a plot of critical mass vs critical volume for Pu-tuff and $\mathrm{Pu}-\mathrm{SiO}_{2}$. This figure is the analog of Figs. 3 and 5. The differences are evident immediately and are significant. The potential for dry criticality of $75 \mathrm{~kg}$, and even much more, is eliminated under these conditions as well.

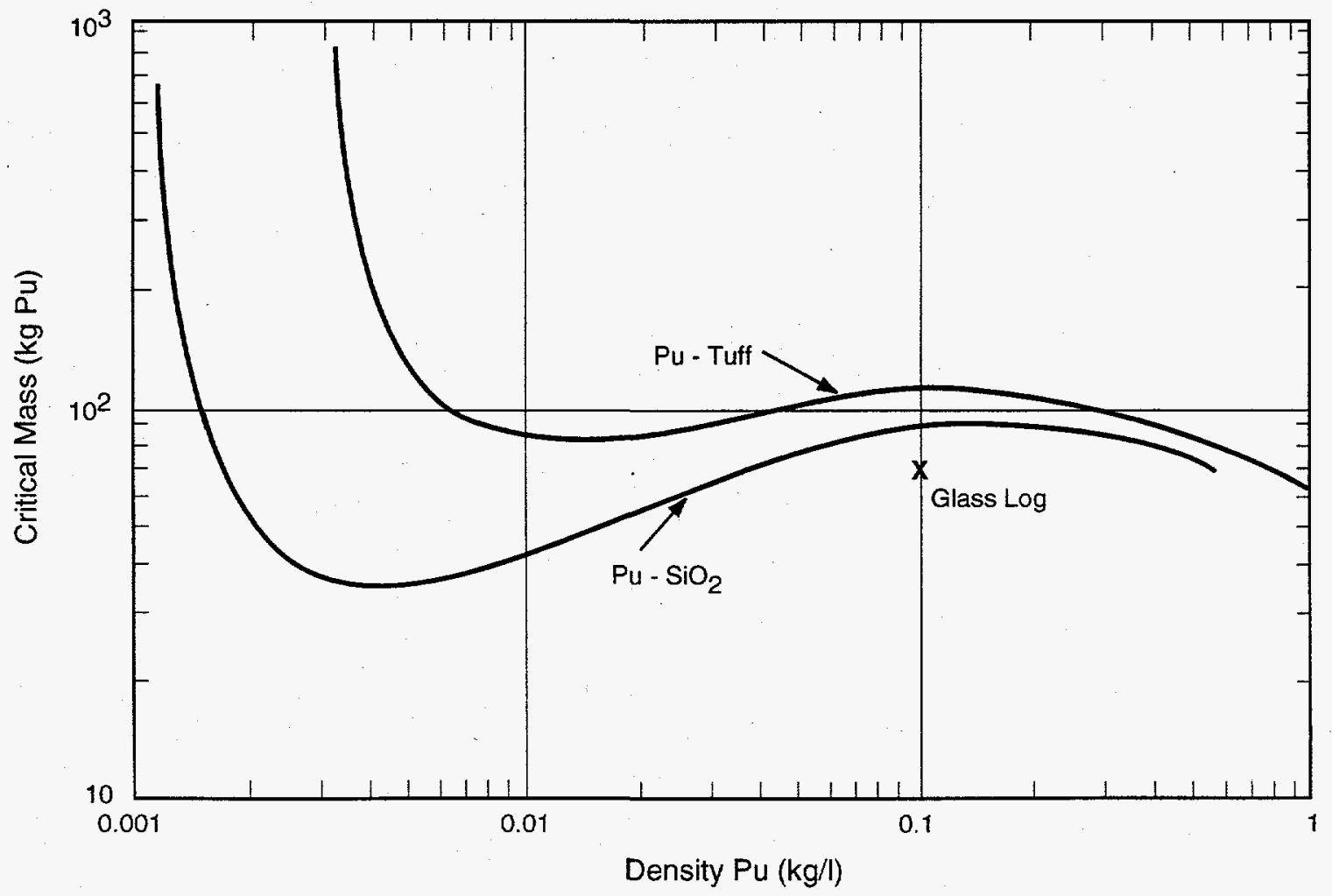

Figure 13. Reflected critical mass of plutonium metal mixed with tuff or $\mathrm{SiO}_{2}$ vs plutonium density (room temperature). This figure is analogous to Figs. 1 and 4. However, the function for Pu-tuff shows a much increased minimum critical mass ( $85 \mathrm{~kg}$ at $0.015 \mathrm{~kg} /$, compared to $35 \mathrm{~kg}$ at $0.004 \mathrm{~kg} / \mathrm{l}$ ), thus eliminating the need to consider the dry criticality as postulated in Ref. 1 . The increased value of the minimum critical density asymptote should be noticed. 
Table V. ${ }^{239}$ Pu Metal - Nevada Tuff Mixtures - Critical Parameters For Tuff-Reflected Spheres at Room Temperature

\begin{tabular}{|c|c|c|c|c|}
\hline $\begin{array}{c}\left(\mathbf{S i}^{239} \mathbf{P u}\right) \mathbf{1} / \mathbf{0 . 7 7} \\
(\text { Atom ratio })\end{array}$ & $\begin{array}{c}\text { Pu Density } \\
(\mathbf{k g} / \mathbf{)}\end{array}$ & $\begin{array}{c}\text { Radius } \\
(\mathbf{c m})\end{array}$ & $\begin{array}{c}\text { Volume } \\
(\text { liters })\end{array}$ & $\begin{array}{c}\text { Mass } \\
(\mathbf{k g ~ P u})\end{array}$ \\
\hline $0.87 \times 10^{0}$ & $1.0 \times 10^{1}$ & 6.27 & $1.04 \times 10^{0}$ & 10.4 \\
\hline $1.75 \times 10^{0}$ & $5.0 \times 10^{0}$ & 9.94 & $4.12 \times 10^{0}$ & 20.6 \\
\hline $2.75 \times 10^{0}$ & $3.18 \times 10^{0}$ & 13.13 & $9.49 \times 10^{0}$ & 30.1 \\
\hline $4.41 \times 10^{0}$ & $1.98 \times 10^{0}$ & 17.25 & $2.15 \times 10^{1}$ & 42.6 \\
\hline $8.75 \times 10^{0}$ & $1.0 \times 10^{0}$ & 24.93 & $6.49 \times 10^{2}$ & 64.9 \\
\hline $1.47 \times 10^{1}$ & $5.96 \times 10^{-1}$ & 32.16 & $1.39 \times 10^{2}$ & 83.1 \\
\hline $4.72 \times 10^{1}$ & $1.85 \times 10^{-1}$ & 52.53 & $6.07 \times 10^{2}$ & 112.6 \\
\hline $1.83 \times 10^{2}$ & $4.77 \times 10^{-2}$ & 81.03 & $2.22 \times 10^{3}$ & 106.2 \\
\hline $7.53 \times 10^{2}$ & $1.16 \times 10^{-2}$ & 120.68 & $7.36 \times 10^{3}$ & 85.6 \\
\hline $1.175 \times 10^{3}$ & $7.40 \times 10^{-3}$ & 144.39 & $1.26 \times 10^{4}$ & 93.3 \\
\hline $1.578 \times 10^{3}$ & $5.54 \times 10^{-3}$ & 170.81 & $2.08 \times 10^{4}$ & 115.7 \\
\hline $1.839 \times 10^{3}$ & $4.76 \times 10^{-3}$ & 192.78 & $3.00 \times 10^{4}$ & 142.9 \\
\hline $2.736 \times 10^{3}$ & $3.20 \times 10^{-3}$ & 361.34 & $1.97 \times 10^{5}$ & 632.4 \\
\hline $2.812 \times 10^{3}$ & $3.11 \times 10^{-3}$ & 398.70 & $2.65 \times 10^{5}$ & 825.7 \\
\hline $2.919 \times 10^{3}$ & $3.00 \times 10^{-3}$ & 466.90 & $4.26 \times 10^{5}$ & 1279.2 \\
\hline
\end{tabular}

Figure 14. Reflected critical mass of plutonium mixed with tuff or $\mathrm{SiO}_{2}$ vs critical volume (room temperature). This figure is analogous to Figs. 3 and 5. Criticality of $75 \mathrm{~kg}$ of plutonium in dry tuff is not possible.

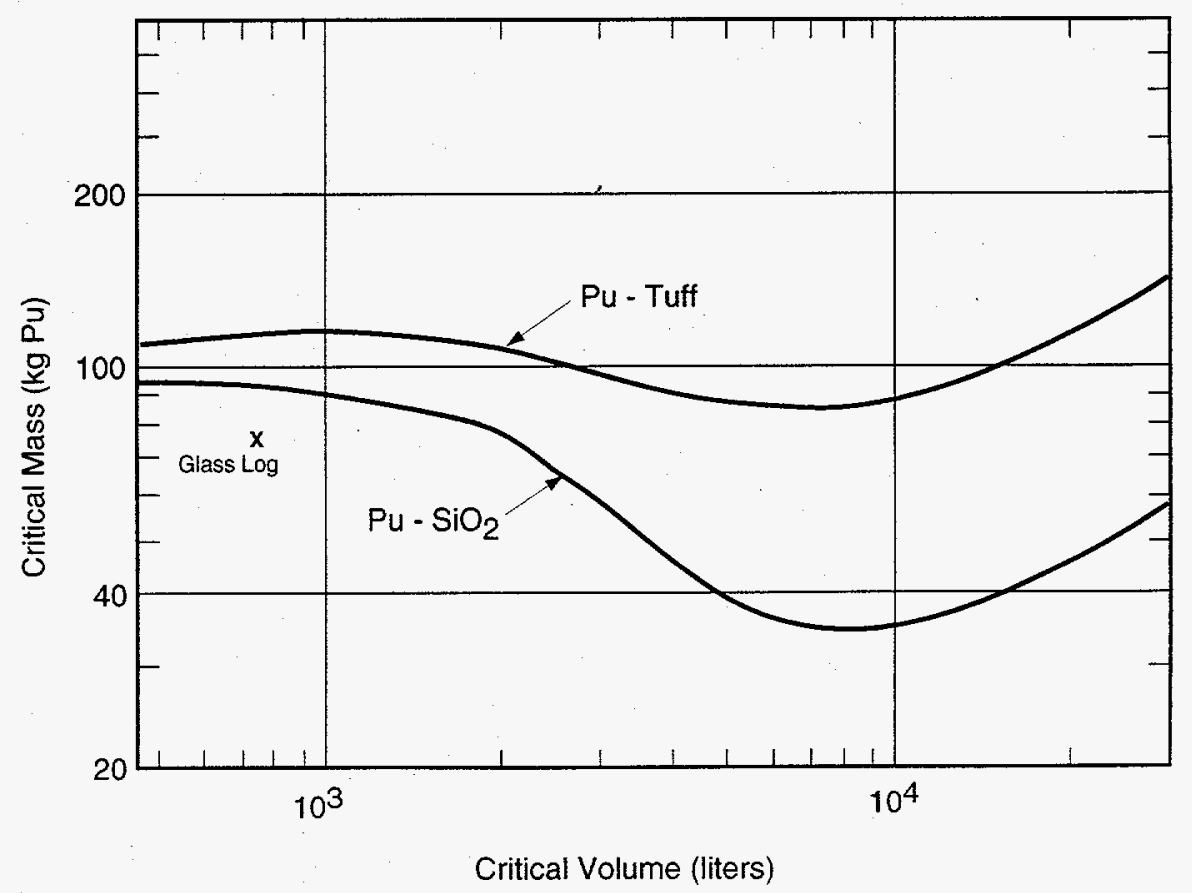




\section{CRITICALITY CALCULATIONS FOR Pu-TUFF-H2O, A THREE-COMPONENT SYSTEM}

The critical data for $\mathrm{Pu}-\mathrm{SiO}_{2}-\mathrm{H}_{2} \mathrm{O}$ mixtures were presented in Fig. 6 and Table III. The comparable data for Pu-Tuff- $\mathrm{H}_{2} \mathrm{O}$ are given in Table VI and illustrated in Fig. 15. The changes that derive from the increased plutonium density at the asymptote at $0.003 \mathrm{~kg} / 1$ are more apparent, as is the ultimate poisoning by hydrogen. The model used for the mixing of water with the Pu-tuff is the displacement model: a given mass of water displaces the appropriate volume of Pu-tuff. However, a different model is possible. This derives from the observation that tuff has a porosity of several percent by volume. Five percent to eleven percent porosity (i.e., void) has been reported (Refs. 5 and 16). This model has been considered and some results are reported in the Appendix. The calculated critical masses differ somewhat from those determined by using the displacement model, but these differences do not affect the final conclusion.

Pu-tuff- $\mathrm{H}_{2} \mathrm{O}$ critical mass data are presented in Fig. 16 as a function of the weight percent of water. The increased effect of the neutron absorbers in tuff is clearly seen in the more restricted range of the functions in this figure. To compare these data with the data of Figs. 8 and 9, the Si/Pu ratios for tuff are multiplied by $1 / 0.77$ and denoted by Si/Pu*.

Table VI. ${ }^{239}$ Pu Metal, Tuff, and $\mathrm{H}_{2} \mathrm{O}$ Mixtures Critical Parameters for Spheres Reflected With Tuff - $\mathrm{H}_{2} \mathrm{O}$ Mixtures at Room Temperature

\begin{tabular}{|c|c|c|c|c|c|}
\hline $\begin{array}{c}\left.\mathbf{( S i}^{239} \mathbf{P u}\right) \mathbf{1 / 0 . 7 7} \\
\text { (Atom ratio) }\end{array}$ & $\begin{array}{c}\text { Water } \\
(\mathrm{wt} \%)\end{array}$ & $\begin{array}{c}\text { Pu Density } \\
(\mathrm{kg} / \mathrm{l})\end{array}$ & $\begin{array}{c}\text { Radius } \\
(\mathrm{cm})\end{array}$ & $\begin{array}{c}\text { Volume } \\
(\text { liters })\end{array}$ & $\begin{array}{c}\text { Mass } \\
(\mathrm{kg} \mathrm{Pu})\end{array}$ \\
\hline 752 & 0.0 & $1.16 \times 10^{-2}$ & 120 & $7.36 \times 10^{3}$ & 85.6 \\
\hline 752 & 1.0 & $1.14 \times 10^{-2}$ & 88.43 & $2.90 \times 10^{3}$ & 32.9 \\
\hline 752 & 2.0 & $1.11 \times 10^{-2}$ & 75.49 & $1.80 \times 10^{3}$ & 20.0 \\
\hline 752 & 3.0 & $1.08 \times 10^{-2}$ & 68.11 & $1.33 \times 10^{3}$ & 14.3 \\
\hline 752 & 5.0 & $1.03 \times 10^{-2}$ & 59.83 & $8.97 \times 10^{2}$ & 9.3 \\
\hline 752 & 7.0 & $9.88 \times 10^{-3}$ & 55.38 & $7.11 \times 10^{2}$ & 7.0 \\
\hline 752 & 10.0 & $9.22 \times 10^{-3}$ & 52.13 & $5.93 \times 10^{2}$ & 5.5 \\
\hline 752 & 13.0 & $8.61 \times 10^{-3}$ & 51.02 & $5.57 \times 10^{2}$ & 4.8 \\
\hline 752 & 15.0 & $8.23 \times 10^{-3}$ & 51.34 & $5.66 \times 10^{2}$ & 4.7 \\
\hline 752 & 18.0 & $7.67 \times 10^{-3}$ & 53.14 & $6.28 \times 10^{2}$ & 4.8 \\
\hline 752 & 20.0 & $7.33 \times 10^{-3}$ & 55.35 & $7.1 \times 10^{2}$ & 5.2 \\
\hline 752 & 25.0 & $6.52 \times 10^{-3}$ & 66.51 & $1.23 \times 10^{3}$ & 8.1 \\
\hline 752 & 30.0 & $5.80 \times 10^{-3}$ & 103.2 & $4.60 \times 10^{3}$ & 26.7 \\
\hline 752 & 31.0 & $5.60 \times 10^{-3}$ & 123.63 & $7.92 \times 10^{3}$ & 44.9 \\
\hline 752 & 33.0 & $5.40 \times 10^{-3}$ & 343.74 & $1.66 \times 10^{5}$ & 898.7 \\
\hline
\end{tabular}


Table VI. ${ }^{239} \mathrm{Pu}$ Metal, Tuff, and $\mathrm{H}_{2} \mathrm{O}$ Mixtures

Critical Parameters for Spheres Reflected With Tuff - $\mathrm{H}_{2} \mathrm{O}$ Mixtures at Room Temperature (continued)

\begin{tabular}{|c|c|c|c|c|c|}
\hline $\begin{array}{c}\left(\mathbf{S i}^{239} \mathbf{P u}\right) \mathbf{1 / 0 . 7 7} \\
(\text { Atom ratio) }\end{array}$ & $\begin{array}{c}\text { Water } \\
(\mathbf{w t} \%)\end{array}$ & $\begin{array}{c}\text { Density } \\
(\mathbf{k g} / \mathbf{l})\end{array}$ & $\begin{array}{c}\text { Radius } \\
(\mathbf{c m})\end{array}$ & $\begin{array}{c}\text { Volume } \\
(\text { liters })\end{array}$ & $\begin{array}{c}\text { Mass } \\
(\mathbf{k g ~ P u})\end{array}$ \\
\hline 1175 & 0.0 & $7.40 \times 10^{-3}$ & 144.39 & $1.26 \times 10^{4}$ & 93.2 \\
\hline 1175 & 1.0 & $7.23 \times 10^{-3}$ & 107.33 & $5.18 \times 10^{3}$ & 37.4 \\
\hline 1175 & 2.0 & $7.06 \times 10^{-3}$ & 93.72 & $3.45 \times 10^{3}$ & 24.4 \\
\hline 1175 & 3.0 & $6.90 \times 10^{-3}$ & 86.51 & $2.71 \times 10^{3}$ & 18.7 \\
\hline 1175 & 4.0 & $6.74 \times 10^{-3}$ & 86.20 & $2.33 \times 10^{3}$ & 15.7 \\
\hline 1175 & 6.0 & $6.43 \times 10^{-3}$ & 78.11 & $2.00 \times 10^{3}$ & 12.9 \\
\hline 1175 & 9.0 & $6.01 \times 10^{-3}$ & 78.71 & $2.04 \times 10^{3}$ & 12.3 \\
\hline 1175 & 11.0 & $5.74 \times 10^{-3}$ & 82.68 & $2.37 \times 10^{3}$ & 13.6 \\
\hline 1175 & 13.0 & $5.48 \times 10^{-3}$ & 90.39 & $3.09 \times 10^{3}$ & 17.0 \\
\hline 1175 & 14.0 & $5.36 \times 10^{-3}$ & 96.36 & $3.75 \times 10^{3}$ & 20.1 \\
\hline 1175 & 16.0 & $5.12 \times 10^{-3}$ & 116.64 & $6.65 \times 10^{3}$ & 34.0 \\
\hline 1175 & 17.0 & $5.00 \times 10^{-3}$ & 136.02 & $1.05 \times 10^{4}$ & 52.8 \\
\hline 1175 & 18.0 & $4.89 \times 10^{-3}$ & 170.16 & $2.06 \times 10^{4}$ & 100.9 \\
\hline 1175 & 19.0 & $4.77 \times 10^{-3}$ & 265.86 & $7.87 \times 10^{4}$ & 376.2 \\
\hline
\end{tabular}

\begin{tabular}{|l|l|l|l|l|r|}
\hline 1570 & 0.0 & $5.54 \times 10^{-3}$ & 170.81 & $2.09 \times 10^{4}$ & 115.7 \\
\hline 1570 & 1.0 & $5.41 \times 10^{-3}$ & 130.85 & $9.38 \times 10^{3}$ & 50.8 \\
\hline 1570 & 2.0 & $5.29 \times 10^{-3}$ & 117.94 & $6.87 \times 10^{3}$ & 36.3 \\
\hline 1570 & 3.0 & $5.16 \times 10^{-3}$ & 112.52 & $5.96 \times 10^{3}$ & 30.8 \\
\hline 1570 & 4.0 & $5.04 \times 10^{-3}$ & 111.05 & $5.73 \times 10^{3}$ & 29.0 \\
\hline 1570 & 5.0 & $4.93 \times 10^{-3}$ & 112.35 & $5.94 \times 10^{3}$ & 29.3 \\
\hline 1570 & 6.0 & $4.82 \times 10^{-3}$ & 116.10 & $6.55 \times 10^{3}$ & 31.6 \\
\hline 1570 & 7.0 & $4.71 \times 10^{-3}$ & 122.66 & $7.73 \times 10^{3}$ & 36.4 \\
\hline 1570 & 8.0 & $4.60 \times 10^{-3}$ & 133.14 & $9.88 \times 10^{3}$ & 45.5 \\
\hline 1570 & 9.0 & $4.50 \times 10^{-3}$ & 150.11 & $1.41 \times 10^{4}$ & 63.8 \\
\hline 1570 & 10.0 & $4.40 \times 10^{-3}$ & 180.50 & $2.46 \times 10^{4}$ & 108.3 \\
\hline 1570 & 11.0 & $4.30 \times 10^{-3}$ & 252.92 & $6.77 \times 10^{4}$ & 291.3 \\
\hline 1570 & 11.2 & $4.28 \times 10^{-3}$ & 282.64 & $9.45 \times 10^{4}$ & 404.7 \\
\hline 1570 & 11.3 & $4.27 \times 10^{-3}$ & 305.37 & $1.19 \times 10^{5}$ & 509.2 \\
\hline
\end{tabular}


Table VI. ${ }^{239}$ Pu Metal, Tuff, and $\mathrm{H}_{2} \mathrm{O}$ Mixtures

Critical Parameters for Spheres Reflected With Tuff - $\mathrm{H}_{2} \mathrm{O}$ Mixtures at Room Temperature (continued)

\begin{tabular}{|c|c|c|c|c|c|}
\hline $\begin{array}{c}\left(\mathbf{S i}{ }^{239} \mathbf{P u}\right) \mathbf{1} / \mathbf{0 . 7 7} \\
\text { (Atom ratio) }\end{array}$ & $\begin{array}{c}\text { Water } \\
(\mathbf{w t} \%)\end{array}$ & $\begin{array}{c}\text { Density } \\
(\mathbf{k g} / \mathbf{)}\end{array}$ & $\begin{array}{c}\text { Radius } \\
(\mathbf{c m})\end{array}$ & $\begin{array}{c}\text { Volume } \\
\text { (liters) }\end{array}$ & $\begin{array}{c}\text { Mass } \\
(\mathbf{k g ~ P u})\end{array}$ \\
\hline 1850 & 0.0 & $4.76 \times 10^{-3}$ & 192.78 & $3.00 \times 10^{4}$ & 142.9 \\
\hline 1850 & 1.0 & $4.65 \times 10^{-3}$ & 151.81 & $1.47 \times 10^{4}$ & 68.2 \\
\hline 1850 & 2.0 & $4.54 \times 10^{-3}$ & 141.23 & $1.18 \times 10^{4}$ & $5 \overrightarrow{3} .6$ \\
\hline 1850 & 3.0 & $4.44 \times 10^{-3}$ & 140.47 & $1.16 \times 10^{4}$ & 51.6 \\
\hline 1850 & 4.0 & $4.34 \times 10^{-3}$ & 145.83 & $1.29 \times 10^{4}$ & 56.4 \\
\hline 1850 & 5.0 & $4.24 \times 10^{-3}$ & 157.79 & $1.65 \times 10^{4}$ & 69.8 \\
\hline 1850 & 6.0 & $4.14 \times 10^{-3}$ & 180.33 & $2.46 \times 10^{4}$ & 101.7 \\
\hline 1850 & 7.0 & $4.04 \times 10^{-3}$ & 227.57 & $4.94 \times 10^{4}$ & 199.8 \\
\hline 1850 & 8.0 & $3.94 \times 10^{-3}$ & 395.28 & $2.59 \times 10^{5}$ & 1023.5 \\
\hline
\end{tabular}

\begin{tabular}{|l|l|l|l|l|l|}
\hline 2750 & 0.0 & $3.20 \times 10^{-3}$ & 361.34 & $1.97 \times 10^{5}$ & 632.4 \\
\hline 2750 & 0.1 & $3.192 \times 10^{-3}$ & 357.04 & $1.91 \times 10^{5}$ & 608.7 \\
\hline 2750 & 0.2 & $3.185 \times 10^{-3}$ & 355.58 & $1.88 \times 10^{5}$ & 599.9 \\
\hline 2750 & 0.3 & $3.177 \times 10^{-3}$ & 356.77 & $1.90 \times 10^{5}$ & 604.5 \\
\hline 2750 & 0.4 & $3.170 \times 10^{-3}$ & 360.42 & $1.96 \times 10^{5}$ & 621.8 \\
\hline 2750 & 0.5 & $3.163 \times 10^{-3}$ & 366.48 & $2.06 \times 10^{5}$ & 652.2 \\
\hline 2750 & 0.6 & $3.156 \times 10^{-3}$ & 375.04 & $2.21 \times 10^{5}$ & 697.3 \\
\hline 2750 & 0.7 & $3.148 \times 10^{-3}$ & 386.45 & $2.42 \times 10^{5}$ & 761.1 \\
\hline 2750 & 0.8 & $3.141 \times 10^{-3}$ & 401.17 & $2.70 \times 10^{5}$ & 849.5 \\
\hline 2750 & 0.9 & $3.133 \times 10^{-3}$ & 420.01 & $3.10 \times 10^{5}$ & 972.6 \\
\hline 2750 & 1.0 & $3.126 \times 10^{-3}$ & 444.23 & $3.67 \times 10^{5}$ & 1148.0 \\
\hline
\end{tabular}




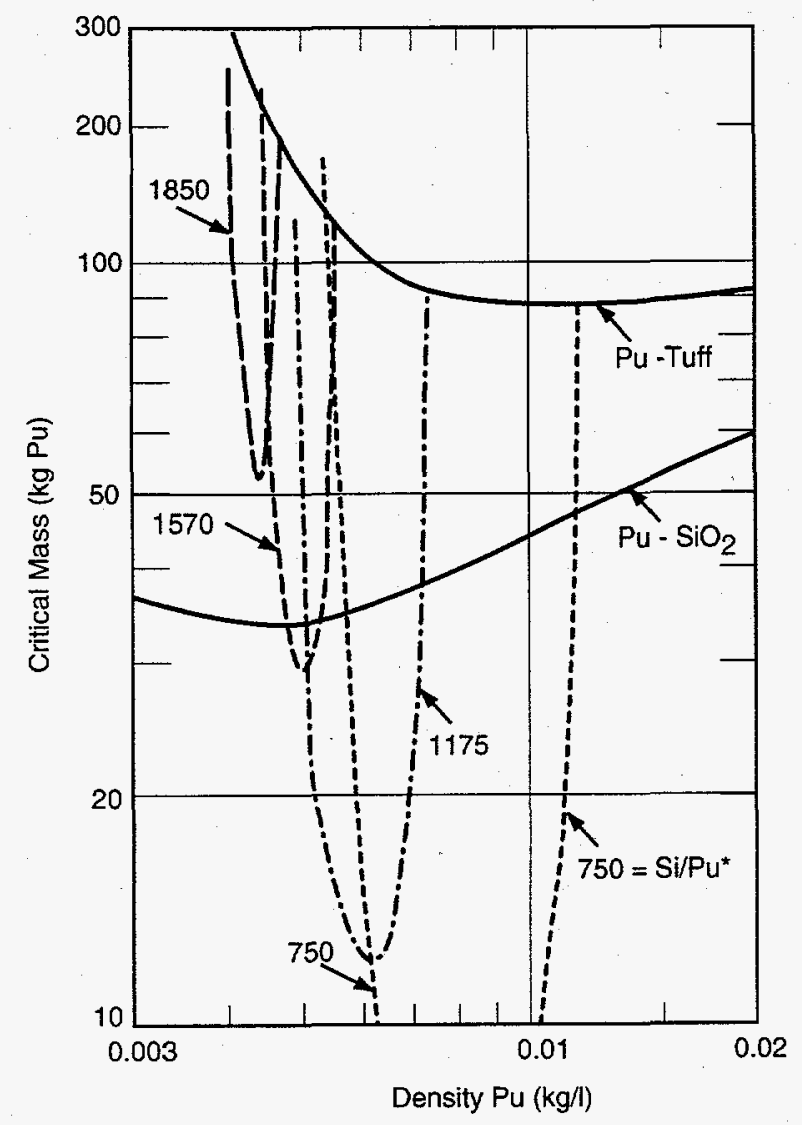

Figure 15. Reflected critical mass of plutonium mixed with tuff and water $v s$ density of plutonium (room temperature). This figure is analogous to Fig. 6 for plutonium mixed with $\mathrm{SiO}_{2}$ and water.

Figure 16. Reflected critical mass of plutonium metal mixed with tuff and water vs weight percent water (room temperature). This figure is analogous to

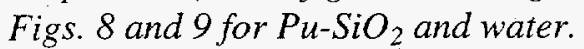

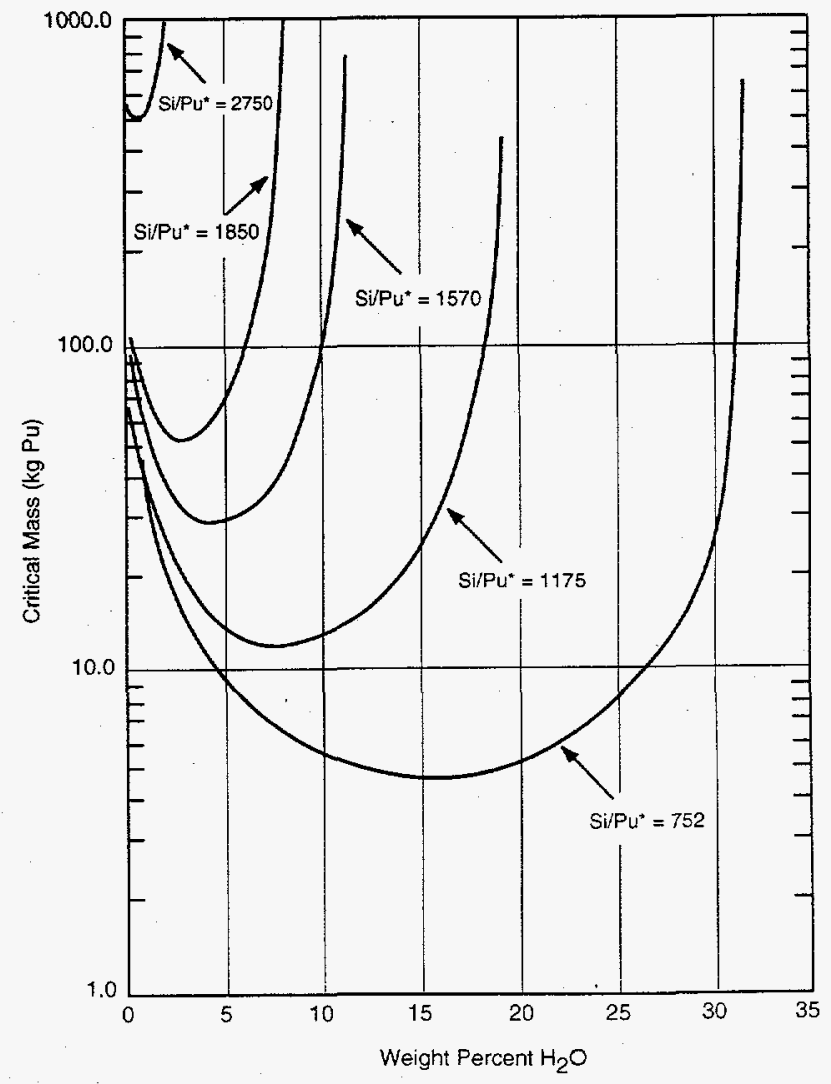




\section{DISCUSSION OF POSTULATES}

a. The Dry Scenario.

The postulated slow geologic expansion of the $\mathrm{Pu}-\mathrm{SiO}_{2} \log$ into surrounding (in this case) tuff is unchanged compared to the pure $\mathrm{Pu}-\mathrm{SiO}_{2}$ case. As mentioned above, the significant difference is that the "dry critical" state is not created because of the criticality characteristics of the Pu-tuff mixtures (Figs. 13 and 14, Table V). The minimum critical mass of plutonium in tuff is greater than $75 \mathrm{~kg}$. The "dry supercriticality" is eliminated for Pu-tuff mixtures. Nevertheless, the dynamic behavior of the $\mathrm{Pu}-\mathrm{SiO}_{2}$ system will be examined in a companion paper on dynamics for the case of pure $\mathrm{Pu} / \mathrm{SiO}_{2}$ mixtures.

\section{b. The Wet Scenario.}

The postulate of mixing water with the $\mathrm{Pu}-\mathrm{SiO}_{2}$ is unchanged for the Pu-tuff system. A water-induced criticality remains possible, even if improbable, and the comparison to the Oklo phenomenon remains valid. The power level would be determined by the flow and amount of water. As with pure $\mathrm{SiO}_{2}$, no explosion should be expected.

c. The Movement of Plutonium into a Wet Stratum.

The postulated mechanism is unchanged. By postulate, much of the $\mathrm{SiO}_{2}$ in the original log (which fixes the plutonium in place) disappears, allowing the plutonium to be mobile and penetrate slowly into a stratum of wet tuff. The addition of plutonium would start at a very high Si/Pu ratio and progress to smaller ratios as more plutonium migrates into the stratum. One constraint is defined for each $\mathrm{Si} / \mathrm{Pu}$ ratio by the water-poisoning asymptote seen on Fig. 16. The locus of these asymptotes is plotted as the upper line on Fig. 17; the water content must be less than this value for criticality to occur. This figure is the analog of Fig. 10 for pure $\mathrm{SiO}_{2}$ diluent.

Figure 17. Silicon/plutonium ratio in tuff multiplied by $1 / 0.77$ (and denoted by Si/P $\left.u^{*}\right)$ vs weight percent water (room temperature). This figure is analogous to $\mathrm{Fig} .10$ for $\mathrm{SiO}_{2}$. The lower, intermediate, and upper limits are derived in the same manner as for Fig. 10. Configurations outside these limits are not of interest. The configurations within the shaded triangles may be unstable. The most severe unstable or autocatalytic mixture is expected to be at $\mathrm{Si} / \mathrm{Pu}=1570$ and $10 \mathrm{wt} \% \mathrm{H}_{2} \mathrm{O}$.

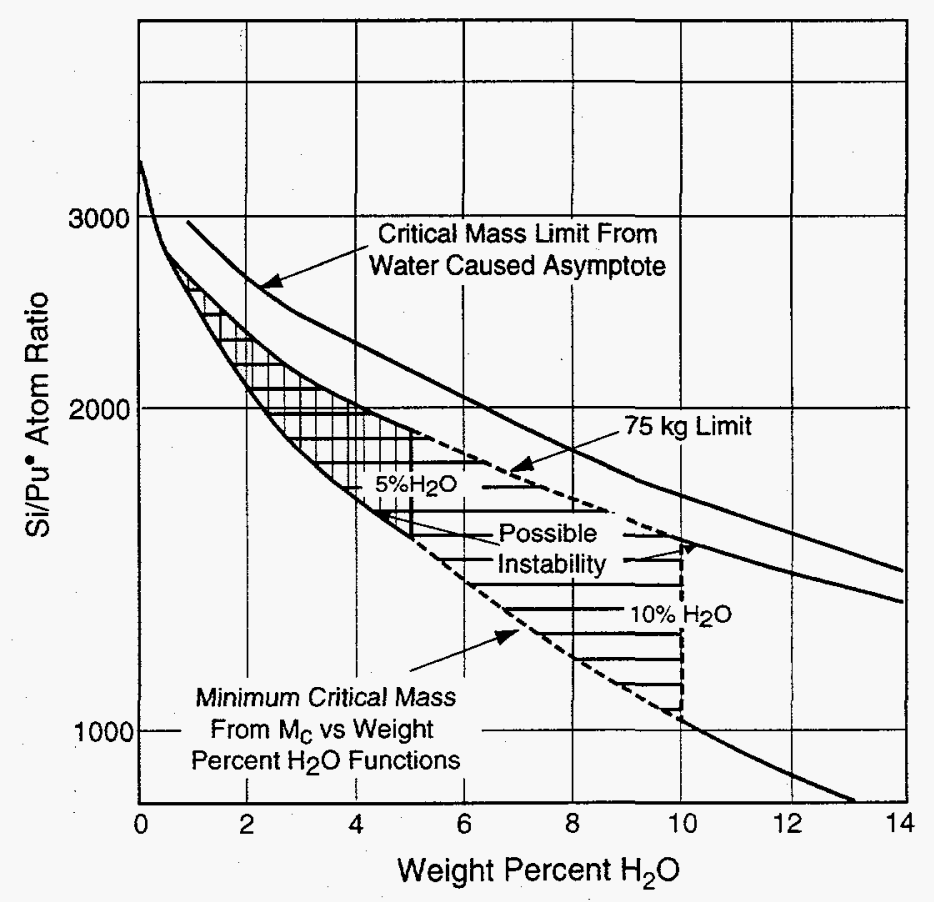

Referring again to Fig. 16, the minimum of each function is the lowest water concentration above which instability or autocatalysis is possible. A lower water concentration cannot lead to instability. The 
locus of these points is plotted on Fig. 17 as the lower line, providing another constraint on the amount of water to be considered.

The limitation set by the mass loading limit of $75 \mathrm{~kg}$ can be read from the functions for each $\mathrm{Si} / \mathrm{Pu} *$ atom ratio on Fig. 16. The locus of these points is plotted on Fig. 17 as the middle line, comparable to Fig. 10 for $\mathrm{SiO}_{2}$.

The final constraint is the amount of water that would actually be found in the tuff. This has been estimated to be about $5 \mathrm{wt} \%$ (Ref. 5). However, twice this amount will be considered to assure conservatism. These constraints are illustrated on Fig. 17 as vertical lines at $5 \%$ and $10 \%$ water content.

The full picture of the constraints for Pu-tuff- $\mathrm{H}_{2} \mathrm{O}$ can be defined as was done for $\mathrm{Pu}-\mathrm{SiO}_{2}-\mathrm{H}_{2} \mathrm{O}$. On Fig. 17, a triangle is defined by the coordinates for $5 \mathrm{wt} \%$ water and $75 \mathrm{~kg}$. These are a Si/Pu* ratio of 2700 and $0.4 \mathrm{wt} \%$ water, 1850 and $5 \mathrm{wt} \%$, and 1450 and $5 \mathrm{wt} \%$. For $10 \%$ water and $75 \mathrm{~kg}$, the coordinates are 2700 and $0.4 \mathrm{wt} \%, 1500$ and $10.0 \mathrm{wt} \%$, and 1100 and $10 \mathrm{wt} \%$. Configurations of $\mathrm{Pu}-\mathrm{Tuff}-\mathrm{H}_{2} \mathrm{O}$ that lie outside these boundaries are not of interest because, as discussed earlier, criticality or autocatalytic behavior or both are not possible.

\section{REACTIVITY ( $\left.k_{\text {eff }}\right)$ CALCULATIONS FOR Pu-TUFF-H2O MIXTURES}

Reactivity calculations have been completed in the same manner as those for the $\mathrm{Pu}-\mathrm{SiO}_{2}-\mathrm{H}_{2} \mathrm{O}$ mixtures. The general characteristics are similar, but details differ significantly. The cases of most interest are the data for a Si/Pu* atom ratio of 1570 . These data are illustrated on Fig. 18 and are presented numerically in Table VII. The masses of plutonium and the initial water content are as follows: Case (1) $404.7 \mathrm{~kg}$ and $11.2 \mathrm{wt} \%$ water; Case (2) $108.3 \mathrm{~kg}$ and $10.0 \mathrm{wt} \%$ water; Case (3) $63.8 \mathrm{~kg}$ and $9 \mathrm{wt} \%$ water; Case (4) $45.5 \mathrm{~kg}$ and $8 \mathrm{wt} \%$ water; and Case (5) $36.4 \mathrm{~kg}$ and $7 \mathrm{wt} \%$ water. These data cluster in the upper right hand corner of the permissible triangle on Fig. 17. This "corner" (10.0 wt \% water, $75 \mathrm{~kg}$ and $\mathrm{Si} / \mathrm{Pu} *$ ratio of 1500 ) is the condition that will lead to the highest $k_{\mathrm{eff}}$ and the largest integral of $k_{\text {eff }}$ as a function of weight percent of water. The reactivity functions of Fig. 18 are almost precisely at the correct spot to examine the most severe limiting case. Case (1) on Fig. 18 has too much plutonium and water; Case (2) exceeds the mass limit but has the correct limiting amount of water. The other three are all within permissible constraints. The maximum $k_{\text {eff }}$ for $75 \mathrm{~kg}$ of plutonium is about 1.06 (by interpolation) when approximately three-fourths of the water is forced out of the system (see Fig. 18).

By examining the data of Figs. 17 and 18, it is apparent that the total energy release can be estimated without the aid of a computer program designed to calculate dynamic behavior. In fact, the mixture or assembly defined by $10 \%$ water in tuff, $75 \mathrm{~kg}$ of plutonium, and a Si/Pu* ratio of about 1500 is close to the most severe test of whether or not an explosion could develop. The configuration most closely approximating this assembly is defined by the data in Table VI for a Si/Pu* of 1570 and Table VII-D and is illustrated in Fig. 18 for the case labelled by $108.3 \mathrm{~kg}$. The mass of $108.3 \mathrm{~kg}$ is greater than the constraint of $75 \mathrm{~kg}$, but this merely introduces an extra measure of conservatism. 


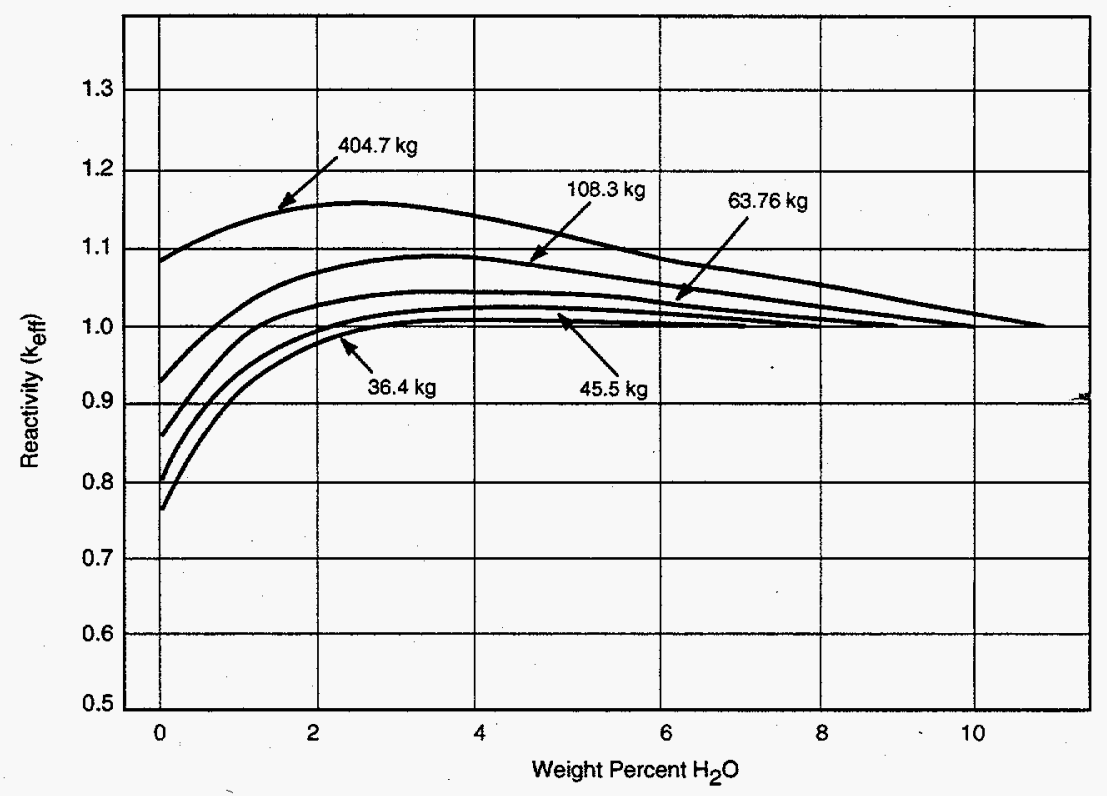

Figure 18. Reactivity ( $k_{\text {eff }}$ ) vs weight percent water for Si/Pu* $=1570$ (tuff) and 404.7 , $108.3,63.76,45.5$, and $36.42 \mathrm{~kg}$ of plutonium (room temperature). These functions lie very close to the most severe configuration defined in Fig. 17. The uppermost function is outside the constraints for both mass of plutonium and weight percent water. The second curve (for $108.3 \mathrm{~kg}$ of plutonium) is satisfactory for the water content, but beyond limits for the mass of plutonium. The lower three functions all lie within the derived limits.

We assume that the configuration has been created and, as stated, it is just critical with $10 \%$ water by weight and $108.3 \mathrm{~kg}$ of plutonium. From Table VI and using a density of $2.38 \mathrm{~kg} / \mathrm{l}$, the total mass of the "core" is $5.85 \times 10^{4} \mathrm{~kg}$. For the accuracy needed here, the mass of water is taken to be $5.85 \times 10^{3} \mathrm{~kg}$.

The assumptions for the power transient are as follows: initially, and during the period of rising power, all the fission energy is deposited into boiling water, with no change in temperature or generation of pressure. The decrease in water content will increase reactivity to a maximum $k_{\text {eff }}$ of 1.080 where the water content is only $2.38 \%$ by weight. The steam is assumed to vanish, an assumption that should increase the energy of the postulated transient. In fact, a significant pressure would be generated by steam, and this pressure would cause expansion and reduction of reactivity; also, should the temperature rise, the temperature coefficient of reactivity for neutrons would be negative.

By reference to Fig. 18, the system would be subcritical even before all the water evaporated. However, for ease of analysis this effect is ignored, and the energy required to evaporate all the water is $1.3 \times 10^{10}$ joules. After this change, the system becomes subcritical, and the reactivity decreases very rapidly. The energy generated after this boiling process and while the power is dropping will be smaller (or certainly not greater) than that generated during the power rise.

If this energy is now used to heat the mass of tuff, the temperature rise would be about $220^{\circ} \mathrm{C}$.

No kinetic energy, dynamic behavior, or explosion will occur. 
Table VII. ${ }^{239} \mathrm{Pu}$, Tuff, and $\mathrm{H}_{2} \mathrm{O}$ Reflected Spheres

Reactivity $\left(k_{\text {eff }}\right)$ for a Si ${ }^{239}$ Pu Ratio of 1570, Several Plutonium Masses, and Water Contents at Room Temperature

A. $\left(\mathrm{Si}^{239} \mathrm{Pu}\right) \mathbf{1 / 0 . 7 7}=\mathbf{1 5 7 0}$

Mass $\mathrm{Pu}=36.4 \mathrm{~kg}$

Density $\mathrm{Pu}=4.71 \times 10^{-3} \mathrm{~kg} / 1$

Volume $=7.73 \times 10^{3}$ liters

\begin{tabular}{|c|c|}
\hline $\begin{array}{c}\text { \% Water } \\
\text { by wt }\end{array}$ & $\boldsymbol{k}_{\text {eff }}$ \\
\hline 7.0 & 1.000 \\
\hline 6.11 & 1.006 \\
\hline 5.21 & 1.010 \\
\hline 4.26 & 1.010 \\
\hline 2.23 & 0.980 \\
\hline 1.14 & 0.925 \\
\hline 0.0 & 0.754 \\
\hline
\end{tabular}

B. $\left(\mathrm{Si}^{239} \mathrm{Pu}\right) \mathbf{1} / 0.77=1570$

Mass $\mathrm{Pu}=45.5 \mathrm{~kg}$

Density $\mathrm{Pu}=4.60 \times 10^{-3} \mathrm{~kg} / 1$

Volume $=9.88 \times 10^{3}$ liters

\begin{tabular}{|c|c|}
\hline $\begin{array}{c}\text { \% Water } \\
\text { by wt }\end{array}$ & $\boldsymbol{k}_{\text {eff }}$ \\
\hline 8.0 & 1.000 \\
\hline 6.25 & 1.017 \\
\hline 4.36 & 1.024 \\
\hline 2.28 & 1.0027 \\
\hline 1.17 & 0.953 \\
\hline 0.0 & 0.787 \\
\hline
\end{tabular}

D. $\left(\mathrm{Si}^{239} \mathrm{Pu}\right) \mathbf{1} / \mathbf{0 . 7 7}=\mathbf{1 5 7 0}$

Mass $\mathrm{Pu}=108.3 \mathrm{~kg}$

Density $\mathrm{Pu}=4.397 \times 10^{-3} \mathrm{~kg} / \mathrm{l}$

Volume $=2.46 \times 10^{4}$ liters

\begin{tabular}{|c|c|}
\hline $\begin{array}{c}\text { \% Water } \\
\text { by wt }\end{array}$ & $\boldsymbol{k}_{\text {eff }}$ \\
\hline 10.00 & 1.000 \\
\hline 8.32 & 1.026 \\
\hline 6.52 & 1.053 \\
\hline 4.55 & 1.076 \\
\hline 2.38 & 1.080 \\
\hline 0.0 & 0.923 \\
\hline
\end{tabular}

E. $\left(\mathrm{Si}^{239} \mathrm{Pu}\right) \mathbf{1} / \mathbf{0 . 7 7}=\mathbf{1 5 7 0}$

Mass $\mathrm{Pu}=404.7 \mathrm{~kg}$

Density $\mathrm{Pu}=4.277 \times 10^{-3} \mathrm{~kg} / 1$

Volume $=9.45 \times 10^{4}$ liters

\begin{tabular}{|c|c|}
\hline $\begin{array}{c}\text { \% Water } \\
\text { by wt }\end{array}$ & $\boldsymbol{k}_{\text {eff }}$ \\
\hline 11.20 & 1.000 \\
\hline 10.22 & 1.018 \\
\hline 8.53 & 1.050 \\
\hline 6.69 & 1.086 \\
\hline 4.67 & 1.124 \\
\hline 2.45 & 1.156 \\
\hline 0.00 & 1.085 \\
\hline
\end{tabular}

C. $\left(\mathrm{Si}^{239} \mathrm{Pu}\right) \mathbf{1} / \mathbf{0 . 7 7}=\mathbf{1 5 7 0}$

Mass $\mathrm{Pu}=63.8 \mathrm{~kg}$

Density $\mathrm{Pu}=4.49 \times 10^{-3} \mathrm{~kg} / \mathrm{l}$

Volume $=1.41 \times 10^{4}$ liters

\begin{tabular}{|c|c|}
\hline $\begin{array}{c}\text { \% Water } \\
\text { by wt }\end{array}$ & $\boldsymbol{k}_{\text {eff }}$ \\
\hline 9.0 & 1.000 \\
\hline 7.28 & 1.022 \\
\hline 5.44 & 1.041 \\
\hline 3.42 & 1.047 \\
\hline 1.19 & 0.995 \\
\hline 0.0 & 0.841 \\
\hline
\end{tabular}


The energy generation cannot be judged definitively on the basis of static criticality calculations alone. We have, however, reached conclusions for the upper limit of the energy generation in one case. The companion paper on dynamics will examine further the generation of fission energy and the possibility of explosive energy release. ${ }^{\dagger}$

\section{SUMMARY AND CONCLUSIONS}

This paper has examined the static criticality aspects of mixtures of plutonium and $\mathrm{SiO}_{2}$; plutonium, $\mathrm{SiO}_{2}$, and water; plutonium and Nevada tuff; and plutonium, Nevada tuff, and water.

A conservative approach was taken by assuming the plutonium was pure ${ }^{239} \mathrm{Pu}$, homogeneously distributed within the moderator/absorber material in a spherical form. Any deviation from these criteria,

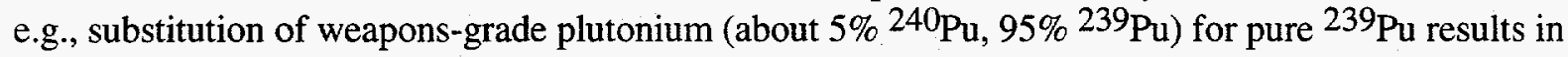
lower neutron multiplication factors and higher critical masses than those calculated in this work. Inclusion of elements found in the Nevada tuff also lowers the calculated neutron multiplication factors. These effects can be significant, especially for the dry criticality case discussed above. All reactivity calculations have included the assumption of uniform, fine-grain mixing of all components throughout.

The several chemical and geologic assumptions made in Refs. 1,2, and 3 are accepted in this study for purposes of calculation only, in spite of the extraordinarily low probability and long time scale they imply; no credence is given to these assumptions because of their application herein.

The general characteristics of fissile systems diluted with a moderator/absorber material were summarized. The qualitative features of the plots of the critical masses of such systems versus the fissile density are generally similar. All exhibit a maximum critical mass with small amounts of diluent, followed by a minimum caused by the moderating effect of the diluent, and finally a low-density unbounded critical mass and critical volume asymptote caused by the neutron absorbing effect or neutron capture of the diluent. Configurations near the asymptote can display instability and possible autocatalytic behavior. The quantitative features, such as the values for the critical masses, the location of the maximum and minimum critical masses, and the location of the asymptote depend on the fissile material and the moderator/absorber materials present.

The postulates of Refs. 1,2, and 3 were characterized as falling into one of the following three cases:

1. expansion of the plutonium into a larger mass of $\mathrm{SiO}_{2}$,

2. water entering the volume of $\mathrm{SiO}_{2}$ that contains the plutonium, and

3. plutonium, as a metal or oxide, entering a wet stratum of rock, These three cases were repeated using Nevada tuff in place of the pure $\mathrm{SiO}_{2}$.

\footnotetext{
In the final stages of preparation of this paper, the authors became aware of the work done in this field by B. F. Gore, U. P. Jenquin, and R. J. Serne of the Pacific Northwest Laboratories. Their publication is identified in Ref. 17. We apologize for the lack of comparisons of comparable criticality situations. This fault will be remedied in a future publication.
} 
These cases were then examined for the potential for autocatalytic behavior. We obtained the following results:

1. The system consisting of pure ${ }^{239} \mathrm{Pu}$ with pure $\mathrm{SiO}_{2}$ as a diluent exhibits the classic dependence of the critical mass on the fissile material density. Thus, a critical system is possible, but very improbable, and autocatalytic behavior is judged to be possible only if assumptions regarded as impossible are accepted. The calculations reported in Ref. 3 will be examined further in a companion paper on the dynamics of these systems. When Nevada tuff is the diluent, nuclear criticality and autocatalytic behavior are not possible for log loadings of less than approximately $84 \mathrm{~kg}$ of ${ }^{239} \mathrm{Pu}$. Plutonium-239 masses greater than about $84 \mathrm{~kg}$ or a substantial variation in the composition of the tuff or a mechanism for "purification" of the tuff will be necessary if criticality is to be achieved. If weapons-grade plutonium ( $5 \%{ }^{240} \mathrm{Pu}$ ) is considered, the requirements are much more stringent. No explosion is possible.

2. For geologic time scales or for processes that add water, criticality is possible for both $\mathrm{SiO}_{2}$ and Nevada tuff diluents. However, no autocatalytic behavior is expected because the system has sufficient time to respond to the reactivity increases (which occur as a result of the addition of water) by ejection of water (e.g., through boiling), which reduces reactivity. A behavior similar to the Oklo phenomena (Ref. 4) is expected, and the total fission energy generated depends on the length of time such a system operates. No explosion is possible.

3. For plutonium entering a wet stratum of $\mathrm{SiO}_{2}$ or Nevada tuff, criticality and autocatalytic behavior are possible, but the $\mathrm{Si} / \mathrm{Pu}$ ratios for which this can occur are constrained by the total amount of plutonium present and by the water content of the strata. These constraints limit the amount of insertion of reactivity when water is removed from the system. The behavior of these wet systems will be examined in a companion paper on dynamics, but an upper limit estimate based only on criticality data shows no kinetic, dynamic, or explosive energy.

\section{Acknowledgments}

The authors would like to thank Randi L. Bagley, Barbara F. Milder, Paul Henriksen, and Carey Parish for their assistance in the typing of the manuscript and preparing tables and figures. We thank A. Petschek, G. E. Hansen, T. F. Stratton, P. Whalen, H. J. C. Kouts, J. Tanner, I. Fergus, and R. A. Van Konynenburg for reviewing this document and suggesting improvements. 


\section{APPENDIX \\ ROCK COMPOSITION USED IN THE ONEDANT AND MCNP MODELS}

The ONEDANT calculations were performed assuming an $S_{n}$ order of 32 and the 16-group HansenRoach Cross Sections with P1 scattering. The spherical model consists of two zones. The inner zone assumes a homogeneous mixture of $\mathrm{Pu}-239$ and $\mathrm{SiO}_{2}$ or tuff and in some cases water. The inner zone contains approximately 200 fine mesh points. The outer zone is the $100-\mathrm{cm}$-thick reflector, which is assumed to be $\mathrm{SiO}_{2}$ or tuff, and in some cases also contains water. The outer zone contains approximately 100 fine mesh points.

For a few special cases, we used the Los Alamos Monte Carlo Neutron Photon (MCNP) code operated in the $k$-code (eigenvalue) and using continuous energy cross sections based on the Evaluated Nuclear Data File, ENDF/B-V and ENDF/B-VI.

Table A.1 contains the actual composition of the tuff [6] and the elements and components that were used in the ONEDANT and MCNP models. Note that some of the cross section data for some of the elements were not available. 
Table A.1. Rock Composition

$\begin{array}{lc}\text { Component } & \mathbf{w t} \% \\ \mathrm{SiO}_{2} & 77.0 \\ \mathrm{TiO}_{2} & 0.1 \\ \mathrm{Al}_{2} \mathrm{O}_{3} & 12.7 \\ \mathrm{FeO} & 0.85 \\ \mathrm{MnO} & 0.06 \\ \mathrm{MgO} & 0.16 \\ \mathrm{CaO} & 0.53 \\ \mathrm{Na} 2 \mathrm{O} & 3.64 \\ \mathrm{~K}_{2} \mathrm{O} & 4.97 \\ \mathrm{P}_{2} \mathrm{O}_{5} & 0.01\end{array}$

Element ppm by weight

$\begin{array}{lr}\mathrm{Sc}^{*} & 2.50 \\ \mathrm{~V} & 5.00 \\ \mathrm{Co} & 0.16 \\ \mathrm{Zn} \mathrm{n}^{* *} & 65.00 \\ \mathrm{As} & - \\ \mathrm{Rb}^{*} & 160.00 \\ \mathrm{Sr} * * & 9.00 \\ \mathrm{Zr} & 108.00 \\ \mathrm{Sb}^{* * *} & 0.33 \\ \mathrm{Cs}^{*} & 6.80 \\ \mathrm{Ba}^{*} & 43.00 \\ \mathrm{Hf} & 4.20 \\ \mathrm{Ta} & 1.50 \\ \mathrm{Th} & 24.00 \\ \mathrm{U} & 4.40 \\ \mathrm{La}^{* * *} & 33.00 \\ \mathrm{Ce}^{* *} & 75.00 \\ \mathrm{Nd}^{*} & 29.00 \\ \mathrm{Sm} & 6.10 \\ \mathrm{Eu} & 0.28 \\ \mathrm{Gd}^{* * *} & 5.50 \\ \mathrm{~Tb}^{* * *} & 0.32 \\ \mathrm{Dy}^{* * *} & 4.80 \\ \mathrm{Tm}^{*} & 0.48 \\ \mathrm{Yb}^{* * *} & 2.70 \\ \mathrm{Lu}^{* * *} & 0.39\end{array}$

* Cross section data not available in ONEDANT.

** Cross section data not available in MCNP.

*** Cross section data not available in both ONEDANT and MCNP. 


\section{Comparison of the Volume Displacement Model with the Porosity Model}

The physical model used to calculate the atom densities for the critical radii and $k_{\text {eff }}$ throughout this study has been the volume displacement model. That is, if, for example, $5 \mathrm{wt} \%$ water is assumed to be mixed with a dry mixture of tuff and plutonium, the volume occupied by the water displaces an equal volume of tuff and plutonium, thus reducing their densities. Another model can be justified and used. This second model recognizes that the tuff has a "porosity" of several percent, sometimes estimated to be as high as $11 \%$. Using this model, the water can be assumed to be simply added to the volume of tuff and plutonium, not changing their densities. A comparison is made in Table A.2 for two Si/Pu* ratios, 1850 and 1570; the displacement model data are taken from Table VI and reproduced here, in part. The porosity model results were obtained with the ONEDANT code and Hansen Roach cross sections.

Table A.2. $\mathrm{Si} / \mathrm{Pu}^{*}=\mathbf{1 5 7 0}$

\begin{tabular}{|c|c|c|c|c|}
\hline $\begin{array}{c}\text { Density } \\
\text { Pu } \\
\mathbf{k g} / \mathbf{l}\end{array}$ & $\begin{array}{c}\text { Displacement } \\
\text { water } \\
(\mathbf{w t} \%)\end{array}$ & $\begin{array}{c}\text { Model } \\
\text { Critical } \\
\text { Mass (kg) }\end{array}$ & $\begin{array}{c}\text { Porosity } \\
\text { Water } \\
(\mathbf{w t} \%)\end{array}$ & $\begin{array}{c}\text { Model } \\
\text { Critical } \\
\text { Mass (kg) }\end{array}$ \\
\hline 0.00554 & 0.0 & 115.7 & 0.0 & 115.66 \\
\hline 0.00554 & 1.0 & 50.8 & 1.05 & 46.91 \\
\hline 0.00554 & 2.0 & 36.3 & 2.087 & 32.16 \\
\hline 0.00554 & 4.0 & 29.0 & 4.088 & 23.83 \\
\hline 0.00554 & 6.0 & 31.6 & 6.01 & 24.69 \\
\hline 0.00554 & 8.0 & 45.5 & 7.85 & 31.07 \\
\hline 0.00554 & 10.0 & 108.3 & 9.63 & 57.55 \\
\hline
\end{tabular}

$\mathrm{Si} / \mathrm{Pu}^{*}=\mathbf{1 8 5 0}$

\begin{tabular}{|c|c|c|c|c|}
\hline $\begin{array}{c}\text { Density } \\
\text { Pu } \\
\text { kg/1 }\end{array}$ & $\begin{array}{c}\text { Displacement } \\
\text { water } \\
\text { (wt\%) }\end{array}$ & $\begin{array}{c}\text { Model } \\
\text { Critical } \\
\text { Mass (kg) }\end{array}$ & $\begin{array}{c}\text { Porosity } \\
\text { Water } \\
\text { (wt\%) }\end{array}$ & $\begin{array}{c}\text { Model } \\
\text { Critical } \\
\text { Mass (kg) }\end{array}$ \\
\hline 0.00476 & 0.0 & 14.29 & 0.0 & 142.8 \\
\hline 0.00476 & 1.0 & 68.2 & 1.05 & 63.36 \\
\hline 0.00476 & 2.0 & 53.6 & 2.08 & 47.97 \\
\hline 0.00476 & 4.0 & 56.4 & 4.09 & 47.11 \\
\hline 0.00476 & 6.0 & 101.7 & 6.01 & 77.43 \\
\hline 0.00476 & 8.0 & 1023.5 & 7.85 & 493.81 \\
\hline
\end{tabular}

These same data are plotted on Fig. A-1 to illustrate the difference graphically. The comparable figure in the body of the text is Fig. 16. The critical masses for the same water concentration can differ by factors up to about 1.4, depending on the amount of water. The pattern, however, is changed not at all and it is this pattern that determines the autocatalytic region of Fig. 17. Thus to use the porosity model would be equally correct, but the fundamental conclusions would be changed only in minor detail. 


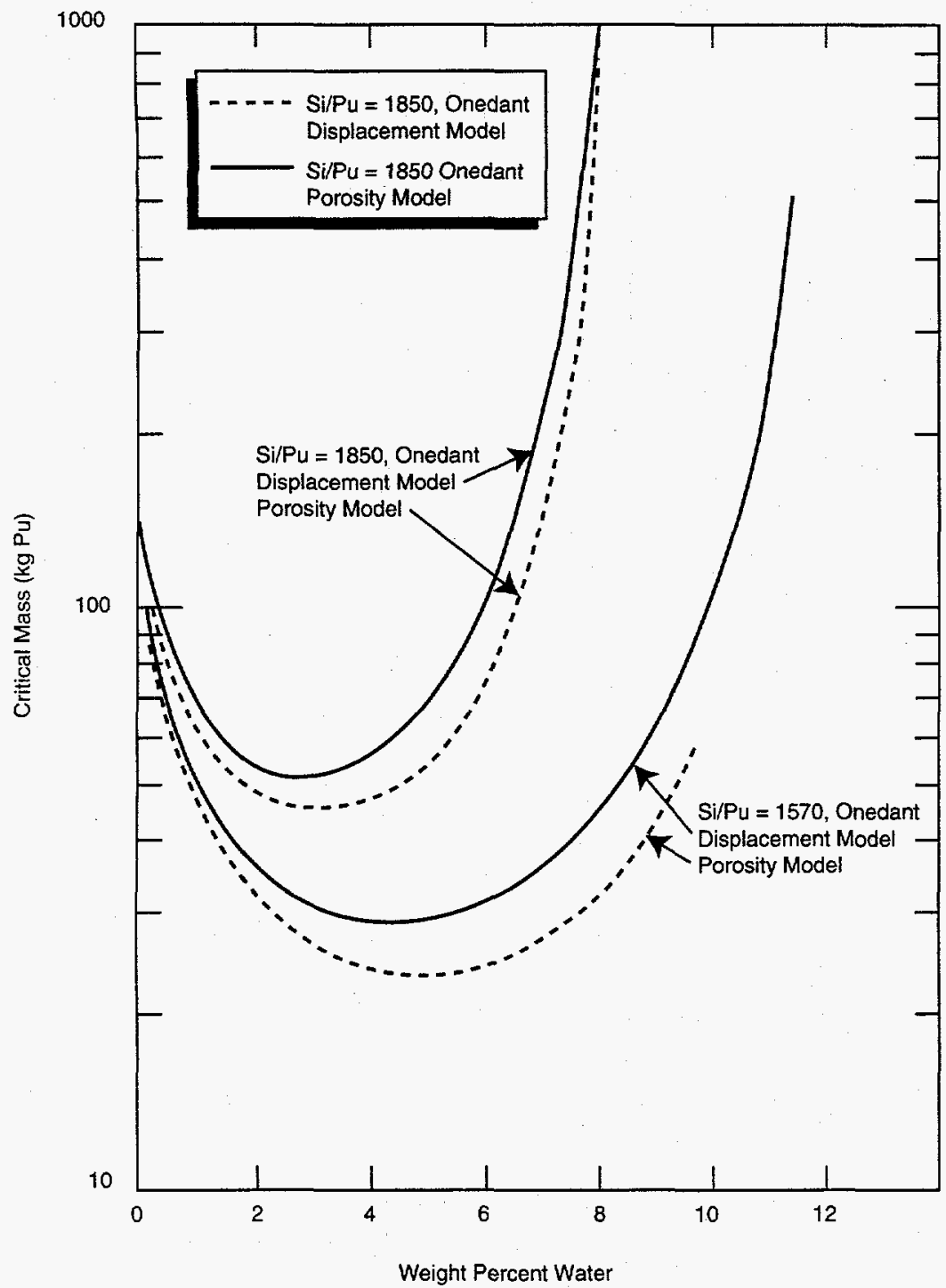

Figure A-1. Reflected critical mass of plutonium metal mixed with tuff and water vs weight percent water. The effect of two models for mixing water with the tuff are illustrated. These are the displacement model, in which the volume of water displaces the appropriate volume of tuff and plutonium, and the porosity model, in which the tuff is assumed to have an existing porosity of up to $11 \%$ of its volume. The water, then, is merely added without changing the density of the solid material. The two assumptions show different critical masses, but have little effect on the conclusions relating to autocatalytic power transients.

\section{Comparison of ONEDANT and MCNP Calculated Results}

A suggestion has been made that because the neutron spectrum of importance in at least part of this study is intermediate, neither fast or thermal, the calculated radii and $k_{\text {eff }}$ would be better determined by using the MCNP computer program with the so-called continuous energy cross sections. This assumption is questionable, but to settle the matter a comparison has been made to ONEDANT data in Table VI and for a Si/Pu* ratio of 1850 . The MCNP program calculates $k_{\text {eff }}$ most easily and these values of $k_{\text {eff }}$ are compared to the $k_{\text {eff }}=1.0$ critical radii calculations in Table A.3, as taken from Table VI in the body of the text. 
Table A.3. ONEDANT-MCNP Comparison

$$
\mathrm{Si} / \mathrm{Pu}^{*}=\mathbf{1 8 5 0}
$$

\begin{tabular}{|c|c|c|c|l|}
\hline $\begin{array}{c}\text { Density } \\
\text { Pu } \\
\mathbf{k g} / \mathbf{l}\end{array}$ & $\begin{array}{c}\text { Water } \\
(\mathbf{w t} \%)\end{array}$ & $\begin{array}{c}\text { ONEDANT } \\
\text { Radius } \\
(\mathbf{c m})\end{array}$ & $\begin{array}{c}\text { ONEDANT } \\
\text { Mass } \\
(\mathbf{k g})\end{array}$ & $\begin{array}{c}\text { MCNP } \\
\boldsymbol{k}_{\text {eff }}\end{array}$ \\
\hline 0.00476 & 0.0 & 192.8 & 142.9 & $1.039 \pm 0.0013$ \\
\hline 0.00476 & 1.05 & 147.0 & 63.4 & $1.0184 \pm 0.0013$ \\
\hline 0.00476 & 2.08 & 134.0 & 48.0 & $1.00656 \pm 0.0012$ \\
\hline 0.00476 & 4.0 & 133.2 & 47.1 & $0.99545 \pm 0.00096$ \\
\hline 0.00476 & 6.0 & 157.2 & 77.4 & $0.99354 \pm 0.00081$ \\
\hline 0.00476 & 7.85 & 291.5 & 493.8 & $0.99244 \pm 0.00077$ \\
\hline
\end{tabular}

The data show that for the case with no water, the $k_{\text {eff }}$ using MCNP is 1.039 , meaning that the critical radius and mass would be smaller. However, when the water content reaches about $2 \%$, the MCNP $k_{\text {eff }}$ is essentially 1.0 and differences in the critical masses would be trivial. If these data were transferred to Fig. 16 the differences could scarcely be seen, and the significant figure, Fig. 17, would not be changed. 


\section{REFERENCES}

1. C. D. Bowman, and F. Venneri, "Nuclear Excursions and Eruptions from Plutonium and Other Fissile Material Stored Underground," Los Alamos National Laboratory, November 22, 1994, draft report.

2. C. D. Bowman and F. Venneri, "Criticality Issues for Thermally Fissile Material in Geologic Storage," Los Alamos National Laboratory document LA-UR-95-504 (January 1995).

3. C. D. Bowman and F. Venneri, "Underground Autocatalytic Criticality from Plutonium and Other Fissile Material," Los Alamos National Laboratory document, LA-UR-94-4022 (January 1995).

4. G. A. Cowan, “A Natural Fission Reactor," Scientific American, 235, (1) 36 (July 1976).

5. Thomas Dey, Los Alamos National Laboratory, private communication (July 1995).

6. D. E. Broxton, R. G. Warren, F. M. Byers, and R. B. Scott, "Chemical and Mineralogic Trends Within the Timber Mountain-Oasis Valley Caldera Complex, Nevada: Evidence for Multiple Cycles of Chemical Evolution in a Long-Lived Silicic Magma System," Journal of Geophysical Research 94 (B5) 5961-5985 (May 10, 1989) Los Alamos National Laboratory document LA-UR-94-4022 (December 1994).

Additional information on tuff and its properties can be found in

6.a. R. F. Roy, A. E. Beck, and Y. S. Touloubian, "Thermophysical Properties of Rocks," in Physical Properties of Rocks and Minerals, Vol. II, W. R. Judd and R. F. Roy, Ed. (McGraw Hill, New York, 1981), pp. 409-502.

6.b. J. R. Kaum and R. J. Bos, "Comparisons of Chemical and Nuclear Explosions: Numerical Simulations of the Non-Proliferation Experiment," Los Alamos National Laboratory report LA12942-MS ( June 1995).

7. R. D. O'Dell, F. W. Brinkly, Jr., and D. R. Marr, "User's Manual for ONEDANT: A Code Package for One-Dimensional, Diffusion-Accelerated, Neutral-Particle Transport," Los Alamos National Laboratory report LA-9184-M (February 1982).

8. B. G. Carlson, "The Numerical Theory of Neutron Transport," in Methods in Computational Physics, Volume 1 (New York, Academic Press, 1963).

9. G. E. Hansen and William H. Roach, "Six and Sixteen Group Cross Sections for Fast and Intermediate Critical Assemblies," Los Alamos Scientific Laboratory report LA-2543-MS, (November 1961).

10. "MCNP, Monte Carlo Neutron Photon code, a General Monte Carlo Code for Neutron and Photon Transport," Los Alamos National Laboratory report LA-7396-M, Rev. 2 (1991).

11. "The Evaluated Nuclear Data File: Version V," available from and maintained by the National Nuclear Data Center, Brookhaven National Laboratory. 
12. W. R. Stratton, "Criticality Data and Factors Affecting Criticality of Single Homogeneous Units," Los Alamos Scientific Laboratory report LA-3612 (July 1964 and September 22, 1967). The Pu- $\mathrm{H}_{2} \mathrm{O}$ data have been extended by one of the authors of this document.

13. H. C. Paxton and N. Pruvost "Critical Dimensions of Systems Containing U-235, Pu-239 and U-233," Los Alamos National Laboratory report LA-10860 (July 1987).

14. J. Robert Oppenheimer and Robert Serber, Letter to R.F. Christy and John A. Wheeler received December 31, 1942, quoted in "Chain Reaction of Pure Fissionable Materials in Solution," CP-400, January 1, 1943. The letter, apparently, has been lost.

15. W. R. Stratton, "Critical Dimensions of U(93.5)-Graphite-Water Spheres, Cylinders, and Slabs," Los Alamos Scientific Laboratory report LA-2955-MS (May 1962).

16. George P. Dix, Raytheon Services Corp., Las Vegas, Nevada, private communication (August 1995).

17. B. F. Gore, U. P. Jenquin, R. J. Serne, "Factors Affecting Criticality for Spent-Fuel Materials in a Geologic Setting," Pacific Northwest Laboratory, Richland, Washington, PNL-3791. 